\title{
Evaluación del impacto de la competencia en un mercado parcialmente protegido: el transporte aéreo interinsular en Canarias (2003-2012) ${ }^{1}$
}

\author{
David Ramos Pérez ${ }^{2}$
}

\begin{abstract}
RESUMEN
En las rutas aéreas interinsulares canarias, declaradas obligación de servicio público en 1998, solo ha existido competencia de forma continuada durante el periodo 2003-2012. El artículo realiza un análisis preliminar de las consecuencias que ha tenido la competencia entre operadores centrándose en cinco aspectos relevantes: la evolución de la oferta, los cambios en la demanda, la ocupación de las rutas, la difusión social del uso del avión y las relaciones laborales. El balance del periodo presenta ciertos claroscuros, ya que aunque de la competencia se derivan algunos impactos positivos para los pasajeros, al considerar el sistema de transporte aéreo de forma integradora también se observan impactos negativos, como la quiebra de uno de los operadores, la degradación de las condiciones laborales y la excesiva polarización de las ayudas públicas a los residentes.
\end{abstract}

Palabras clave: Transporte aéreo, liberalización, competencia, Canarias.

\begin{abstract}
In the inter-island air routes in the Canary Islands, were declared an obligation of the public service in 1998; market competition has only existed in a continuous manner during the period from 2003-2012. This paper presents a preliminary analysis of the consequences of competition between air carriers focusing on five aspects: the evolution of supply, changes in demand, who holds routes, the social diffusion of the air transport use among the local population and labor relations. Our overall assessment of the period contains some grey area, nevertheless competition had some positive impacts for passengers. Considering the air transport system as a whole, some negative impacts were also observed, such as the bankruptcy of one of air carriers, the degradation of labor conditions and the excessive polarization of public aid to island residents.
\end{abstract}

Key words: Air transport, liberalization, competition, Canary Islands.

1 Este artículo es una versión revisada, actualizada y notablemente ampliada de la comunicación "La competencia en el transporte aéreo interinsular canario (2003-2012)", presentada en octubre de 2013 en el XXIII Congreso de la Asociación de Geógrafos Españoles celebrado en Palma de Mallorca (Balea- res). Artículo recibido el 1 de diciembre de 2013, aceptado el 29 de enero de 2015, corregido el 30 de marzo de 2015.

2 Departamento de Geografía, Universidad de Salamanca (España). E-mail: a13004@usal.es 
El impacto espacial de la liberalización del transporte aéreo en la Unión Europea se ha convertido en un campo de estudio fecundo para la Geografía del Transporte. Sin embargo, una revisión de la literatura académica muestra un mayor interés por los análisis a escala comunitaria (Burghouwt, 2007; Dobruszkes, 2008 y 2009; Graham, 1998) que por aquellos centrados en la escala nacional. Aunque encontramos aportaciones de geógrafos relativas al Reino Unido (Graham \& Guyer, 2000), Francia (Zembri, 2000 y 2007), Alemania (Behnen, 2004; Pantazis \& Liefner, 2006), Noruega (Lian, 2010) y Grecia (Papatheodorou \& Arvanitis, 2009), a pesar del tiempo transcurrido desde el inicio de la liberalización, no se observan líneas de trabajo sistemáticas al respecto que permitan una lectura continuada de las transformaciones en curso. Ello también es de aplicación al caso español, donde la limitada atención que la comunidad geográfica ha prestado al proceso de liberalización es si cabe más llamativa, tanto por la dimensión de su mercado interno como por la rápida progresión experimentada por las compañías de bajo coste en el mismo. Algunos trabajos recientes suponen un punto de inflexión en esta situación de olvido, habiéndose abordado las dinámicas de los pequeños aeropuertos regionales (Gámir y Ramos, 2011); la distribución y el papel desempeñados por los subsidios públicos encubiertos en la oferta de algunos aeropuertos (Ramos et al., 2013) y los niveles de conectividad del sistema aeroportuario en el contexto de la racionalización de la red de Iberia (Suau-Sánchez \& Burghouwt, 2012) así como los cambios en la distribución de la capacidad de los aeropuertos observada en la primera década del siglo XXI (Suau-Sánchez \& Burghouwt, 2011).

Llama la atención la ausencia de contribuciones específicas sobre los efectos de la liberalización en la oferta de plazas y frecuencias de las distintas rutas nacionales, la desigual difusión de la competencia en el mercado interior, la estrategia competitiva de las compañías aéreas y la evolución de su cuota de mercado o el impacto de la liberalización en las tarifas. A finales de los noventa, cuando la liberalización aún estaba en sus inicios, estas cuestiones suscitaron el interés de la economista Belén Rey, que dedicó su Tesis Doctoral y algunas publicaciones posteriores a las mismas (Rey, 2000 y 2003). Actualmente son también economistas los que han retomado el interés por estos temas, como Fageda et al. (2011), con su estudio de la estrategia competitiva en materia de tarifas seguida por Iberia en Barcelona, o Betancor y Viecens (2012) y su reciente informe sobre la competencia en el mercado español de transporte aéreo. Los aspectos mencionados, aunque resulten aparentemente básicos, son claves para entender el desigual impacto espacial de la liberalización, consecuencia de una difusión polarizada de la competencia que no ha afectado de la misma forma a todas las rutas y aeropuertos.

Teniendo en cuenta ese contexto, este artículo pretende solventar algunas de las lagunas detectadas para un segmento concreto: las rutas interinsulares del archipiélago canario. Aunque existen ya varias aportaciones sobre dichos servicios (Hernández Luis, 1994, 2004 y 2010; Ramos Pérez, 2001), aún no se ha llevado a cabo ningún balance del periodo 2003-2012, el único en el que de forma constante se ha verificado la existencia de competencia en algunas rutas. El artículo realiza un análisis de las consecuencias que ha tenido la competencia entre operadores centrándose en seis aspectos clave que abordamos de forma consecutiva: (i) la oferta de frecuencias y plazas; (ii) los cambios observados en la demanda; (iii) el grado de ocupación de las rutas; (iii) la funcionalidad horaria de los servicios; (iv) el precio medio de los trayectos y la difusión social del uso del modo aéreo; y (v) los cambios en las relaciones laborales en las compañías aéreas. Previamente se presentará el mercado interinsular canario, a lo que seguirá una breve reflexión teórica sobre el papel del transporte aéreo en el desarrollo de los territorios insulares así como una pequeña nota respecto a la metodología y fuentes empleadas en el estudio.

\section{El mercado interinsular de transporte aéreo en Canarias}

El mercado interior de transporte aéreo en España presenta algunas particularidades derivadas de la configuración geográfica del país, lo que permite individualizar distintos submercados con características diferenciadas: intra-Peninsular, Canarias-Península, 
Baleares-Península, Melilla-Península, interinsular canario e interinsular balear. En lo que respecta a las relaciones interinsulares del archipiélago canario, han aportado durante los últimos 15 años en torno al 8,5\% del total de pasajeros interiores, alcanzando un máximo de 3,5 millones en el año 2007, fecha en la que también se registraba el mayor número de pasajeros interiores de la historia del país, 43,2 millones. Sin embargo, el año 2012 se cerraba con poco más de 2,8 millones y un descenso del $15 \%$ respecto al ejercicio anterior, contracción que se acentuó en 2013 , donde un nuevo descenso del 13\%, situó el tráfico interinsular por debajo de los 2,5 millones de pasajeros, una cifra similar a la registrada en 2003. La prolongada crisis económica que sufre España, que afecta de forma particular al archipiélago canario, donde la tasa de paro se mantiene ocho puntos por encima de la media nacional desde el año 2009, es la principal causa explicativa de esta caída. Aunque el cese de operaciones de Islas Airways en octubre de 2012 pudo haber acentuado la misma, el contexto económico general resulta mucho más relevante. De hecho, estando muy lejos de los niveles de competencia observados hasta 2012, una la leve mejora de los indicadores macroeconómicos y la ligerísima reducción del desempleo ha propiciado en 2014 un repunte del tráfico del 6,8\%, muy superior al del conjunto del mercado interior $(2,1 \%)$, elevando los pasajeros interinsulares a 2,6 millones.

Algunas de las cifras comentadas muestran de forma evidente la magnitud de este submercado en términos de tráfico. Su relevancia queda aún más reforzada por el hecho de que cuatro rutas interinsulares se sitúan año tras año entre las veinte primeras por tráfico de pasajeros del mercado interior (Cuadro $N^{\circ} 1$ ). Además, entre las otras siete rutas interinsulares que se operaban en 2014, tres superaban ampliamente los 100.000 pasajeros y una se aproximaba a los 90.000, por lo que solo en tres casos la demanda es exigua (Figura $\mathrm{N}^{0} 1$ ). Por ello no es de extrañar que desde 1997, fecha en la que toma cuerpo la completa liberalización del mercado de

Cuadro $\mathrm{N}^{\circ} 1$

Principales rutas del mercado interior español por volumen de pasajeros en 2014

\begin{tabular}{|c|c|c|c|}
\hline Orden & Ruta & Pasajeros & $\mathrm{N}^{\circ}$ compañías \\
\hline 1 & Madrid - Barcelona & 2.203 .671 & 3 \\
\hline 2 & Barcelona - Palma de Mallorca & 1.408 .057 & 3 \\
\hline 3 & Madrid - Palma de Mallorca & 1.278 .406 & 3 \\
\hline 4 & Madrid - Gran Canaria & 1.198 .008 & 3 \\
\hline 5 & Madrid - Tenerife Norte & 1.094 .996 & 3 \\
\hline 6 & Barcelona - Ibiza & 861.974 & 3 \\
\hline 7 & Barcelona - Sevilla & 809.180 & 2 \\
\hline 8 & Barcelona - Menorca & 636.380 & 3 \\
\hline 9 & Madrid - Bilbao & 616.633 & 2 \\
\hline 10 & Gran Canaria - Tenerife Norte & 582.036 & 2 \\
\hline 11 & Madrid - Ibiza & 575.393 & 3 \\
\hline 12 & Barcelona - Málaga & 551.878 & 2 \\
\hline 13 & Madrid - A Coruña & 534.057 & 2 \\
\hline 14 & Madrid - Santiago & 490.037 & 2 \\
\hline 15 & Barcelona - Bilbao & 486.301 & 1 \\
\hline 16 & Gran Canaria - Lanzarote & 486.210 & 2 \\
\hline 17 & Tenerife Norte - La Palma & 474.976 & 2 \\
\hline 18 & Madrid - Vigo & 456.427 & 2 \\
\hline 19 & Gran Canaria- Fuerteventura & 401.853 & 2 \\
\hline 20 & Madrid - Asturias & 392.196 & 2 \\
\hline
\end{tabular}

FUENTE: Servidor estadístico de AENA (http://estadisticas.aena.es) 
Figura $\mathrm{N}^{0} 1$

Pasajeros aéreos transportados en líneas interinsulares en 2014

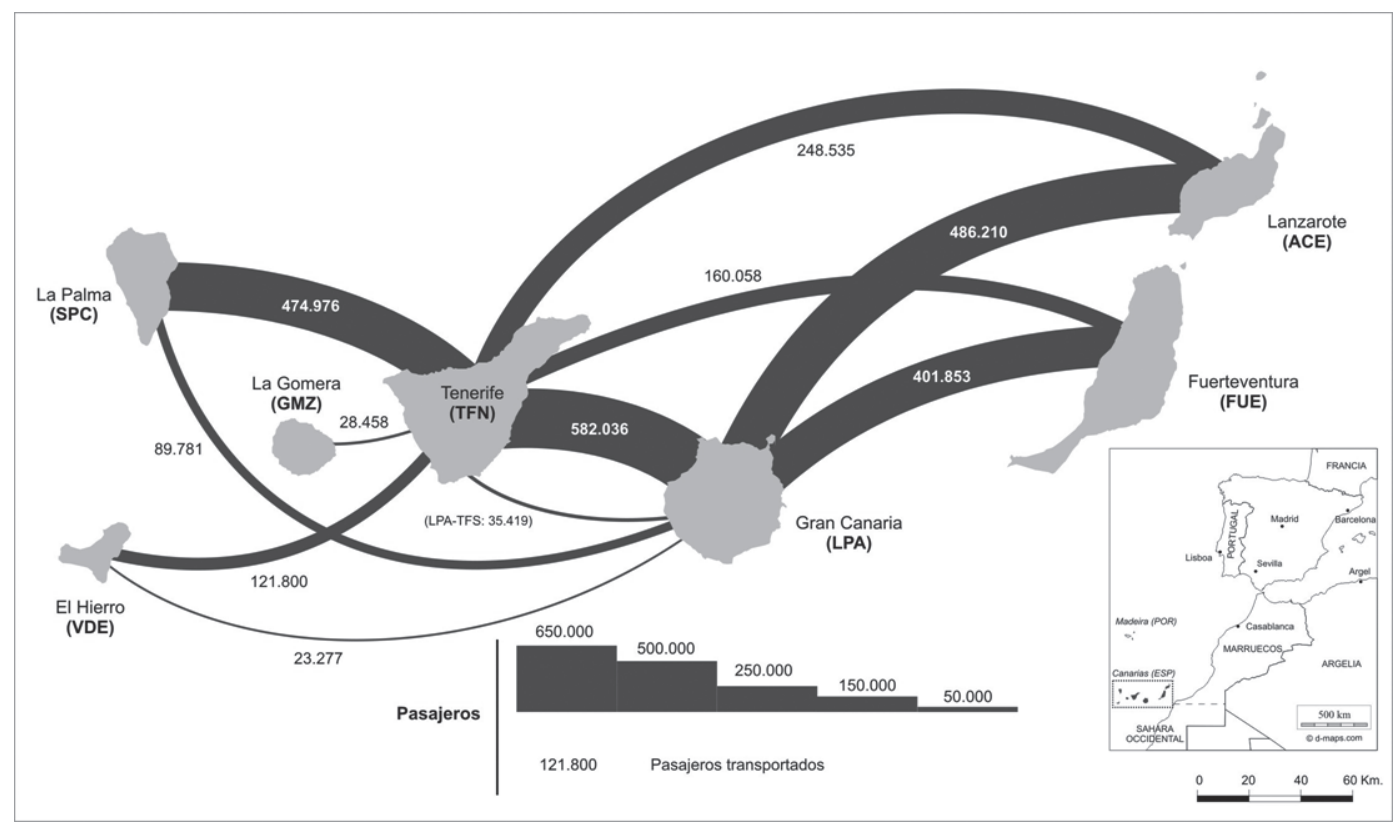

Fuente: Elaboración propi en base a Servidor estadístico de AENA (http://estadisticas.aena.es)

transporte aéreo en el interior de la Unión Europea $^{3}$, varios operadores hayan intentado competir en las rutas interinsulares con la antigua compañía pública Binter Canarias. Y ello a pesar de la existencia de una declaración obligación de servicio público (OSP) que afecta a trece de ellas. Dicha declara-

3 Aunque la liberación del mercado interior de Estados Unidos en 1978 motivó varios estudios sobre la implantación de medidas similares en la entonces Comunidad Económica Europea (CEE), será tras la firma del Acta Única Europea en 1986 cuando se acelerará la toma de decisiones respecto a la liberalización del sector. Dicho tratado transformaba la CEE en la Unión Europea, apostando por la creación a partir de 1993 de un espacio sin fronteras interiores, en el que la libre circulación de mercancías, personas, servicios y capitales estaría garantizada. Ello iba asociado a la liberalización de diferentes mercados, como el de transporte aéreo, que dio sus primeros pasos en 1987 y se adoptó definitivamente de forma escalonada entre 1993 y 1997. Su aprobación restringió a la mínima expresión la capacidad de los poderes públicos para determinar las rutas aéreas a operar, su oferta en cuanto a frecuencias y asientos y las tarifas aplicadas, limitando su papel a la supervisión del sector. ción, que constituye tras la liberalización el único mecanismo legal de intervención pública en el mercado (Dobruszkes, 2007), no implica la concesión automática de la ruta a un único operador en régimen de monopolio a cambio de una compensación económica por cumplir con los requisitos impuestos. Ello solo ocurre cuando ninguna compañía muestra interés en operar la ruta respetando las condiciones fijadas, algo que en el mercado interinsular canario únicamente sucede en los tres enlaces con menor demanda de pasajeros mencionados (Figura $N^{\circ} 1$ ).

Sin embargo, tal y como comprobaremos, la OSP es sumamente relevante desde el punto de vista tarifario y de la oferta mínima de vuelos. De hecho, su existencia impide el aumento de las tarifas por encima de un determinado valor máximo, así como la reducción de las frecuencias operadas por debajo del mínimo estipulado, aun en un contexto de reducción de la demanda como el observado. Por ello, a diferencia de lo que ocurre en un mercado completamente liberalizado, la competencia no resulta aquí tan determinante para la generación de demanda. 


\section{El transporte aéreo, el desarrollo insular y la protección del mercado}

Una pregunta clave que emerge tras esta somera presentación del mercado interinsular es si existen razones objetivas que justifiquen la protección de las rutas interinsulares. Es más, algunos autores han planteado la posibilidad de eliminar la declaración de OSP al menos para las rutas que canalizan un mayor número de pasajeros, ya que la elevada demanda aseguraría su continuidad al margen de la actual regulación (Betancor y Viecens, 2012). La OSP del año 1998 se justificaba atendiendo a las "circunstancias derivadas del hecho insular" (BOE, 1998), confiriendo así a los servicios interinsulares de transporte aéreo en Canarias una cierta singularidad respecto a otro tipo de enlaces aéreos que permanecen al margen de la protección pública. Es decir, se asumía el planteamiento clásico de que la condición insular genera un conjunto de desventajas para el desarrollo de estos territorios a cuya resolución puede contribuir significativamente el transporte aéreo (Hoyle, 1999). Entre ellas podemos citar desde un mayor coste para el acceso a los principales mercados, tanto para pasajeros como para mercancías, hasta una cierta infradotación en cuanto a servicios públicos y privados, lo que implica necesariamente un desplazamiento en barco o avión (Murillo Fort, 1992; Goizart Cardosa, 2014), dependencia que se extiende también a determinados contactos con familiares y amigos o al disfrute de unas vacaciones (Halpern \& Bråthen, 2011).

Por tanto, este argumento implícitamente asocia los territorios insulares con espacios periféricos en lo que respecta a su integración en la economía-mundo capitalista, situación que en buena medida derivaría de su enclavamiento (Debrie \& Steck, 2001). De ahí la idea de que una mejora de las conexiones con los espacios centrales puede aumentar su productividad como consecuencia de un incremento y diversificación de los vínculos entre los distintos agentes económicos. A este respecto, y trabajando en territorios rurales periféricos del norte de Noruega, pero por sus características asimilables a espacios insulares, Halpern y Bråthen (2011) encontraron una estrecha relación entre la calidad de la oferta de transporte aéreo y un conjunto de impactos catalíticos capaces de repercutir en la capacidad de estos territorios para fijar población, desarrollarse turísticamente o atraer ciertas actividades económicas.

Por otro lado, como el grado de enclavamiento es variable, algunos autores plantean la necesidad de superar una concepción unívoca de la insularidad, aceptando que las desventajas asociadas a la misma varían sustancialmente según la isla considerada. En ese sentido, Taglioni (2006), a partir del trabajo de Nicolas (2005) centrado en Martinica y Guadalupe, propone una gradación de la insularidad en función de la intensidad con la que la isla se relaciona con la economíamundo, distinguiendo entre hipoinsularidad, insularidad e hiperinsularidad. En el primer caso se trataría de una suerte de insularidad atenuada, donde se encontrarían aquellas islas mejor integradas en la economía-mundo, con elevados niveles de desarrollo o una notable vinculación político-económica con un territorio continental del que dependen. La ausencia de continuidad territorial derivada de la existencia de una frontera oceánica quedaría aquí minimizada por una óptima conectividad marítima y aérea, asociada en buena medida a su mayor tamaño demográfico y/o la concentración del poder político. En estas islas se diluyen muchas de las desventajas habitualmente asociadas a la condición insular, de ahí que Nicolas (2005) llegue al extremo de denominarlas "apéndices continentales". En los archipiélagos que constituyen unidades políticas, las diferencias en la intensidad de la insularidad se muestran con notable claridad, cobrando sentido los conceptos de insularidad e hiperinsularidad para referirse a aquellas islas cuya integración en la economía-mundo es mucho más frágil. En Canarias, solo las islas de Gran Canaria y Tenerife, que históricamente han desempeñado una función central en el conjunto del archipiélago y mantienen una elevada conectividad con la España peninsular, habrían alcanzado la situación hipoinsularidad. Las restantes islas estarían claramente marcadas por su carácter periférico dentro del propio archipiélago, si bien distan de constituir un todo homogéneo, pudiendo considerarse que algunas experimentan una situación de hiperinsularidad (La Gomera, El Hierro, La Graciosa) y otras de simple insularidad (Lanzarote, 
Fuerteventura, La Palma). En todo caso, es en ambos grupos en los que se manifiestan con claridad las desventajas asociadas al hecho insular antes mencionadas y su mayor dependencia del transporte, lo que tiene un reflejo en el mayor uso de los desplazamientos interinsulares que hacen sus residentes ${ }^{4}$.

Sin embargo, conviene ser cautelosos respecto a la existencia de una relación causa-efecto automática entre la ruptura de la mencionada frontera oceánica y el desarrollo económico de las islas. Aunque la relación entre transporte aéreo y turismo es innegable en un espacio insular, no existen evidencias tan sólidas respecto al papel que la mejora de la conectividad aérea puede propiciar en otros ámbitos. Como tempranamente señaló Offner (1993), la relación entre transporte, transformación de las estructuras territoriales y desarrollo está lejos de ser un proceso mecánico. Es más, algunos economistas señalan que conviene no perder de vista que una reducción de los costes de transporte entre territorios centrales y periféricos puede ser muy negativa para el tejido económico de estos últimos, ya que al abaratar la importación de productos manufacturados se reducen los estímulos para la industrialización, lo que lleva a la especialización de dichos espacios en actividades de bajo valor añadido, como la agricultura o el turismo (Krugman \& Venables, 1995).

En el caso de los tres principales departamentos insulares de ultramar franceses (Martinica, Guadalupe y La Reunión), la excelente conectividad aérea y marítima de la que disfrutan no ha propiciado un cambio profundo en su estructura económica, notablemente especializada en monocultivos agrícolas y excesivamente dependiente de la Francia continental. Como apunta Gay (2008), las élites económicas de estos territorios históricamente rechazaron estrategias de desarrollo económico más autocentradas, en las que veían un riesgo para los beneficios de

\footnotetext{
4 Según datos suministrados por el Ministerio de Fomento, el 40,6\% de los pasajeros que viajaron con un billete bonificado en las rutas interinsulares en el año 2013 residía en alguna de esas seis islas, cuando apenas concentran el $17 \%$ de la población del archipiélago.
}

la actividad agroexportadora y comercial que estaba, y continúa estando, bajo su control. En Canarias, si bien la mejora de la accesibilidad aérea fue básica para el extraordinario desarrollo alcanzado por el turismo, el sector industrial apenas tiene expresión por razones similares a las expuestas: el escaso interés mostrado por la burguesía comercial y agroexportadora en su desarrollo (Guerra Palmero, 2005). En este archipiélago a lo que se llega es a una sustitución de los antiguos monocultivos agrícolas por el nuevo monocultivo que supone el turismo.

Estos planteamientos en modo alguno niegan que puedan existir impactos económicos asociados al transporte aéreo, ni tampoco la relevancia que los mencionados impactos catalíticos puedan tener para ciertas economías insulares, pero sí matizan la magnitud de los mismos para no caer en un verdadero determinismo tecnológico que excluya la multiplicidad de factores que influyen en el mayor o menor desarrollo alcanzado por un territorio. Es decir, salvo excepciones, una adecuada dotación de transporte es condición necesaria pero no suficiente para la transformación económica de un territorio. Por otro lado, tampoco se rechaza que en las islas pueda existir un enclavamiento más o menos pronunciado o ciertas especificidades físicas derivadas de su tamaño y aislamiento relativo, pero sin elevar esos hechos a categorías absolutas, convirtiendo la insularidad en una suerte de insularismo que condena a las islas, por el mero hecho de serlo, al desempeño de un papel marginal o periférico en la economía-mundo (Taglioni, 2010).

Volviendo ahora al interrogante con que abríamos este apartado, a la luz de lo expuesto resulta evidente que las islas afectadas por la insularidad y la hiperinsularidad, que además suelen combinar tamaño reducido y poca población, son las más vulnerables a las incertidumbres asociadas a un mercado de transporte aéreo liberalizado. $\mathrm{Y}$ es en ellas donde probablemente, solo mediante la intervención pública se puede alcanzar una oferta mínima de frecuencias y plazas aéreas adecuada para minimizar las desventajas del hecho insular, equiparando así sus posibilidades de desarrollo a las que existen en otros territorios continentales. A diferencia de lo que ocurre con otras rutas europeas en 
las que se ha impuesto OSP como resultado de las presiones políticas locales (Williams y Pagliari, 2004), puede considerarse que en el caso de las rutas interinsulares canarias, posiblemente con la excepción de la conexión Tenerife-Gran Canaria, la OSP sí presenta el carácter de política territorial al servicio de sociedades marcadas por su carácter de periferia económica y por la ausencia de verdaderas alternativas de transporte.

\section{Metodología y fuentes}

Para evaluar el impacto de la competencia en los aspectos mencionados en la introducción se estudia la evolución que presentan algunas variables relacionadas con los mismos (número de frecuencias y plazas, ocupación de los servicios, funcionalidad horaria, número de pasajeros, tarifas, salarios de los trabajadores de las aerolíneas) a lo largo del periodo considerado. Se toman como referencias temporales comparativas los meses de febrero de 2003, momento previo a la entrada del segundo operador en el mercado interinsular, febrero de 2013, al objeto de calibrar efectos asociados a la salida de dicha compañía ocurrida en octubre de 2012 y febrero de 2015, fecha en la que se ha consolidado un nuevo operador en dos rutas. Cuando resulta pertinente se tienen en cuenta en el análisis los umbrales mínimos que, para algunas de las variables señaladas, determinan las obligaciones de servicio público que afectan a las rutas interinsulares. Por otro lado, en lo que respecta a la funcionalidad horaria de los servicios se sigue la metodología específica diseñada por Hernández Luis (1994). El estudio de los cambios en las relaciones laborales se realiza a partir de dos perfiles concretos de trabajadores (pilotos y tripulantes de cabina de pasajeros, TCP) de los que podemos deducir su salario básico a partir de las tablas salariales recogidas en los convenios colectivos de las diferentes compañías.

La información utilizada proviene de diversas fuentes. La base de datos de la OAG ofrece datos fiables de la oferta diaria de frecuencias y asientos en las distintas rutas, así como de la programación horaria de las mismas. El servidor estadístico de AENA permite acceder a los datos de la demanda desagregados por rutas desde el año 1999 y mediante cálculos sencillos, combinando los datos de pasajeros, operaciones realizadas y configuración de los aviones utilizados en las mismas, puede obtenerse una aproximación a los coeficientes de ocupación de las distintas rutas. Los datos reales de ocupación están en poder de la Dirección General de Aviación Civil (DGAC), que desde hace algunos años ha dejado de publicarlos.

Para la aproximación a la difusión social del modo aéreo entre la población residente se contará con algunos datos derivados de la explotación estadística de los cupones de vuelo vendidos por la compañías. Como la citada DGAC se ha negado en varias ocasiones a suministrarnos dicha información, los datos se han obtenido a partir de la reciente explotación de los mismos realizada por el Instituto de Estadística de Canarias (ISTAC), de las preguntas al Gobierno presentadas por el senador Narvay Quintero y de las intervenciones en sede parlamentaria de la Ministra de Fomento, Ana Pastor. Finalmente, el análisis de las tarifas se basa en un informe elaborado por el Ministerio de Fomento en el año 2008 sobre el impacto en el precio de los billetes del aumento de la bonificación a los residentes en las islas Baleares, Canarias, Ceuta y Melilla. Informe que ha dejado de estar disponible en la web del Ministerio y que tampoco se suministra cuando se solicita formalmente.

\section{La competencia y su impacto en la oferta}

El cese temporal de operaciones anunciado por Islas Airways el 15 de octubre de 2012 cerraba un periodo de más de 9 años que puede considerarse la primera etapa de amplia y prolongada concurrencia en el mercado interinsular canario, dada la escasa duración de las experiencias anteriores (Ramos Pérez, 2001). Las seis rutas interinsulares que han contado con una oferta significativa de frecuencias y asientos de Islas Airways, y en las que por tanto ha podido existir competencia entre operadores, son aquellas que han concentrado entre el $86 \%$ y el $89 \%$ de la demanda durante el periodo 2003-2012. Ello no hace sino confirmar que al liberalizar el mercado, el potencial para la incorporación de nuevos operadores queda circunscrito, 
salvo excepciones, a las rutas con mayor volumen de tráfico. En ellas son mayores las posibilidades de obtener una cuota de mercado que permita alcanzar un cierto margen de beneficios, por lo que seguirán siendo el objetivo principal de nuevos operadores que se interesen por el mercado interinsular.

La presencia de Islas Airways fue desigual en dichas rutas a lo largo de estos nueve años. Se ha mantenido constante en las rutas La Palma-Tenerife y Fuerteventura-Gran Canaria, controlando siempre más del $20 \%$ de la oferta y superando durante amplios lapsos de tiempo el 30\% (Figura № 2). También ha operado siempre la ruta Tenerife-Gran Canaria, aunque de una forma menos relevante, pues nunca llegó a alcanzar el $20 \%$ de la oferta. En las restantes ha estado presente de forma estable desde finales del año 2006, realizando durante 2008 una clara apuesta por las rutas que conectan Fuerteventura y Lanzarote con Tenerife, en las que llegó a superar durante algunos meses más del $30 \%$ de la oferta total de frecuencias y plazas. A ese periodo siguió una etapa de clara retracción que tiene su punto de inflexión a mediados de 2010. Paradójicamente, en un momento en el que la crisis económica y financiera se acentúa, Islas Airways hará una fuerte apuesta por Lanzarote, multiplicando sus frecuencias en las conexiones con Gran Canaria y Tenerife.

Figura $\mathrm{N}^{\circ} 2$

Cuota de mercado de Islas Airways sobre la oferta de plazas por rutas (2004-2012)

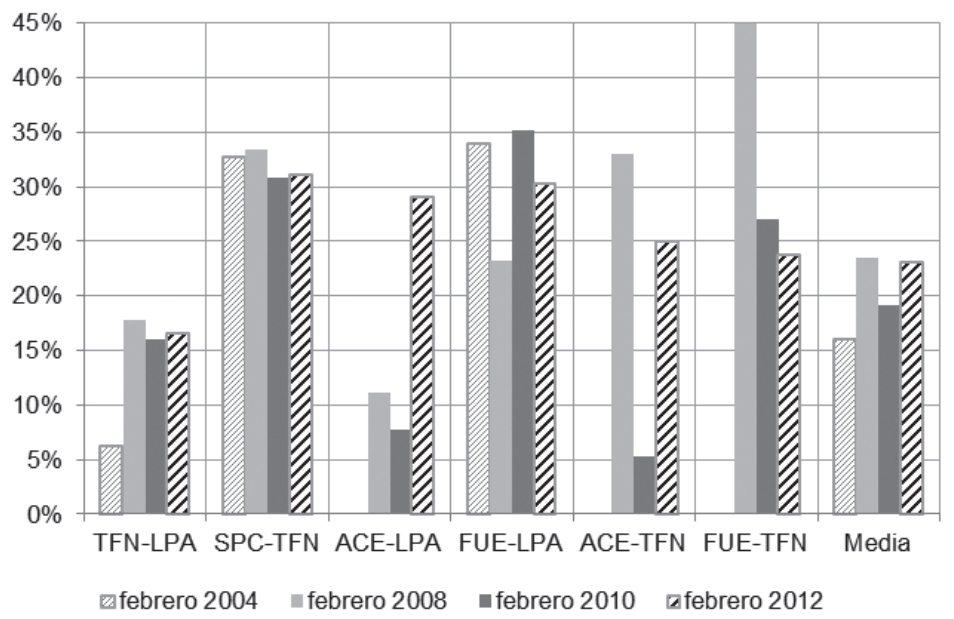

Fuente: Elaboración propia en base a datos OAG.

La respuesta que Binter Canarias dio a la irrupción de Islas Airways ha estado caracterizada por el aumento o reducción de su oferta semanal de vuelos y plazas en función de la expansión o contracción de la red que operaba su competidora. En todo caso, durante todo el periodo de concurrencia siempre se han superado los valores mínimos de frecuencias y asientos estipulados en la declaración de OSP de 1998. De hecho, en febrero de 2003, justo antes de la entrada de Islas Airways, la programación de Binter Canarias ya superaba esos umbrales en la mayor parte de las rutas (Cuadro $N^{\circ} 2$ y No 3 ). Con la entrada de Islas Airways en 2004 se incrementa el margen que existe respecto a los valores mínimos que establece la OSP. Así, en febrero de ese año se operaban diariamente casi 30 frecuencias más de las estipuladas y se superaba en 27.000 plazas la oferta semanal mínima.

En ese contexto alcista se procede a la revisión de las OSP para adecuarlas al auge 


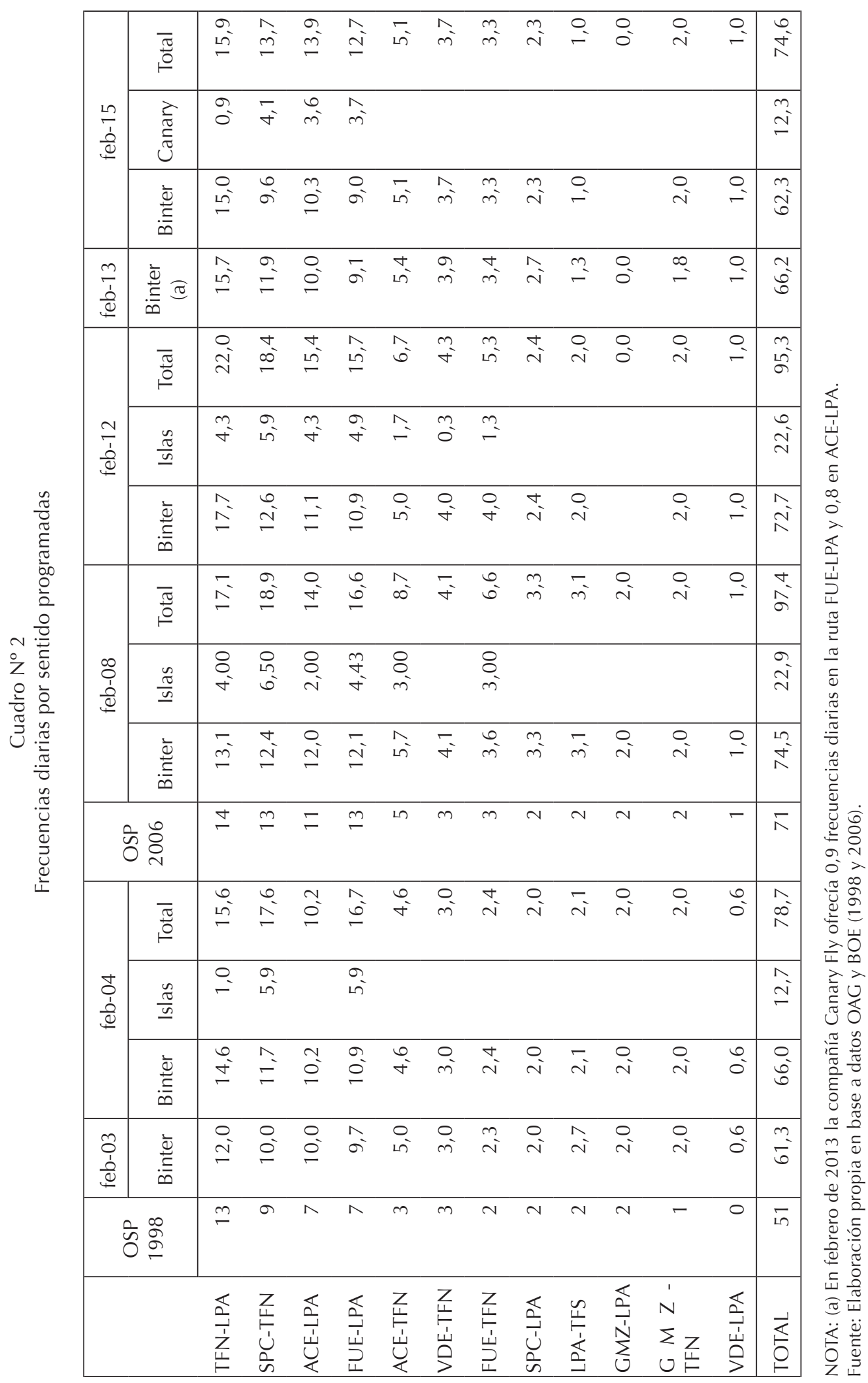




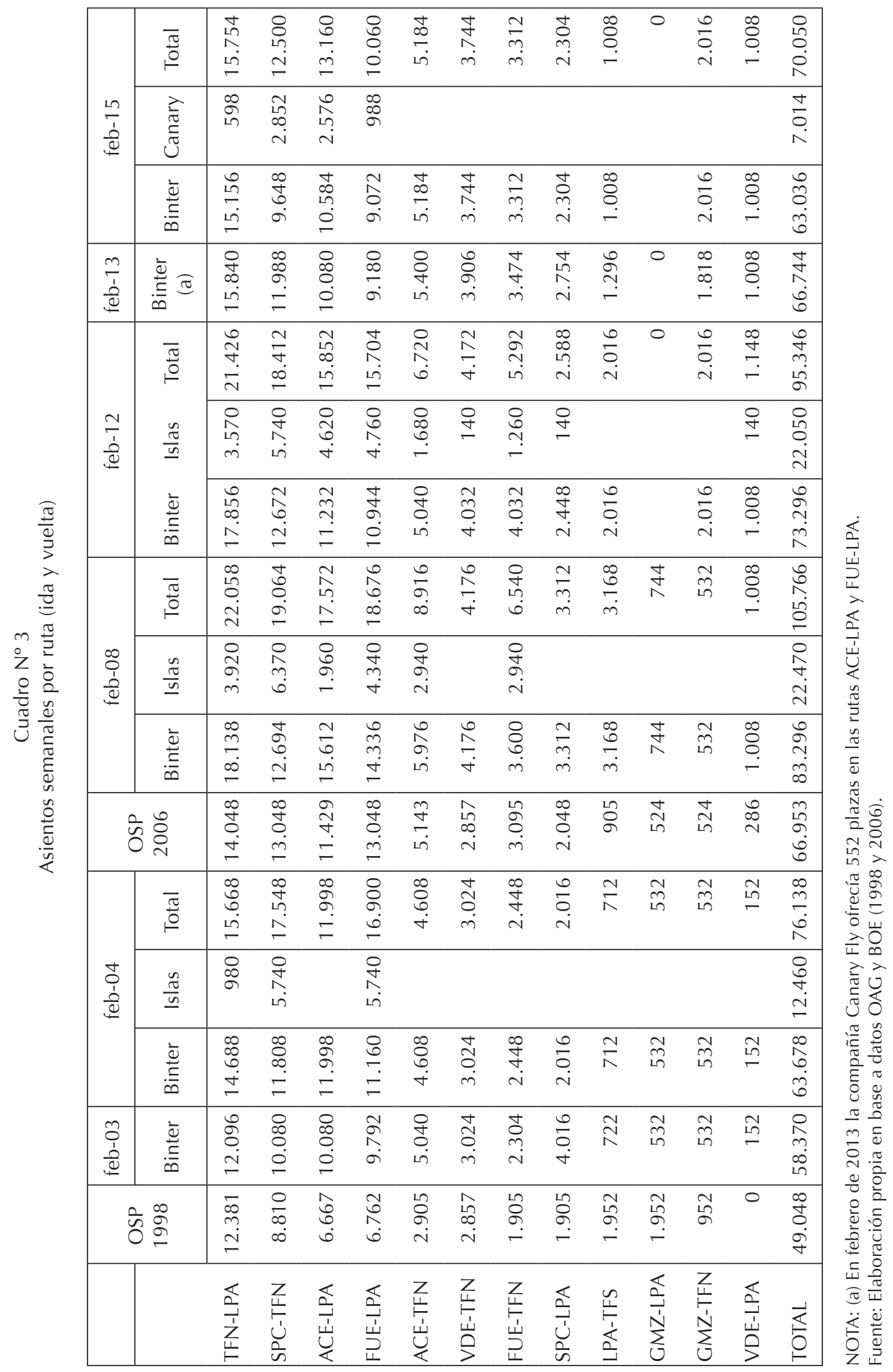


experimentado por la demanda, tal y como se afirma en la exposición de motivos del texto (BOE, 2006). De alguna manera ello implicaba dejar atrás el objetivo fijado en 1998 de "articular una intervención pública, dirigida a hacer posible la existencia de una oferta de servicios suficiente", para diseñar un esquema cambiante en función de las variaciones de la demanda. Hernández Luis (2010) parece coincidir con dicho enfoque dinámico, al señalar que las OSP de 1996 estaban lejos de la realidad del mercado interinsular de la primera década del siglo XXI. Sin embargo, a nuestro juicio, ese no es el objetivo de una OSP, sino aquel que se explicitaba en 1996. Y lo que se entiende por "suficiente" debería fijarse en función de un amplio abanico de criterios, sin limitarlo exclusivamente a la variación de la demanda. Ello no es un debate menor, pues en un contexto de reducción acelerada de la demanda, alguien podría plantear que la declaración de OSP debería modificarse para adecuarla a la realidad presente del mercado interinsular.

De hecho, tanto en febrero de 2008 como en febrero de 2012, la programación conjunta de ambas compañías superaba ampliamente los mínimos de la nueva OSP. Es más, por sí sola, la oferta de Binter Canarias se aproximaba o incluso superaba en la mayoría de las rutas los mencionados umbrales, especialmente en aquellas en las que competía con Islas Airways. Así, en febrero de 2012, en el conjunto de rutas sujetas a OSP, se superaba en 24 frecuencias el mínimo legal fijado, lo que implicaba incrementar en más de 28.000 plazas la oferta semanal mínima establecida.

La situación cambió notablemente tras la desaparición de Islas Airways y el desplome de la demanda. Los ajustes efectuados por Binter Canarias se centraron en aquellas rutas en las que las competencia era más intensa (La Palma-Tenerife, Lanzarote-Gran Canaria y Fuerteventura-Gran Canaria), situándose todas ellas en enero de 2013 por debajo de los umbrales mínimos fijados por la OSP de 2006 pero todavía por encima de los valores de la OSP de 1998. Esta situación, que es legal gracias a una salvaguarda establecida en el artículo nueve de la declaración de OSP, no puede prolongarse más allá de dos temporadas IATA sin un nuevo acuerdo del Consejo de Ministros al respecto. De ahí la importancia de definir lo que se entiende por "oferta suficiente" para las necesidades del archipiélago al margen de la evolución de la demanda. Sin embargo, la incorporación de Canary Fly al mercado interinsular ha posibilitado que en febrero de 2015 vuelvan a cumplirse los valores establecidos en la OSP de 2006.

\section{La evolución de las tarifas interinsulares en un contexto de competencia}

Teóricamente, la existencia de competencia en el mercado interinsular debería haber propiciado la reducción de las tarifas con el objetivo de captar un mayor número de pasajeros. Pero al menos dos factores hacen que sea sumamente complejo determinar el impacto que la misma ha tenido en la reducción de las tarifas medias por trayecto. El primero es el hecho de que tarifas máximas estén reguladas por la declaración de OSP vigente y que dichos valores sean relativamente inferiores a los que se encuentran en rutas no protegidas de características similares, tal y como han puesto de manifiesto Calzada y Fageda (2011). Y el segundo, el cambio en la bonificación para desplazamientos aéreos que disfrutan en España los residentes en territorios extra-peninsulares, que entre 1998 y 2007 ha aumentado del $10 \%$ al $50 \%$ de la tarifa aplicada.

Este último hecho supuso que entre ambas fechas el precio medio en términos reales de los trayectos interinsulares descendiera en un $41 \%$ para los residentes en Canarias (Figura $\left.\mathrm{N}^{\circ} 3\right)$. Sin embargo, para los no residentes los precios aumentaron en esos años, lo que evidencia que el menor coste de los billetes interinsulares para quienes viven en las islas Canarias fue sobre todo fruto del incremento de la subvención por residencia. Solo entre 2003 y 2004, fechas en las que la bonificación se mantuvo estable en un 33\%, puede achacarse íntegramente el descenso tarifario observado a la irrupción de Islas Airways en el mercado interinsular canario.

Desde 2007 la bonificación a los residentes vuelve a mantenerse estable, en este caso en el $50 \%$, lo que permite evaluar el efecto sobre las tarifas que ha tenido la presencia 
Figura $\mathrm{N}^{\circ} 3$

Evolución del precio medio de los trayectos interinsulares (1993-2012)

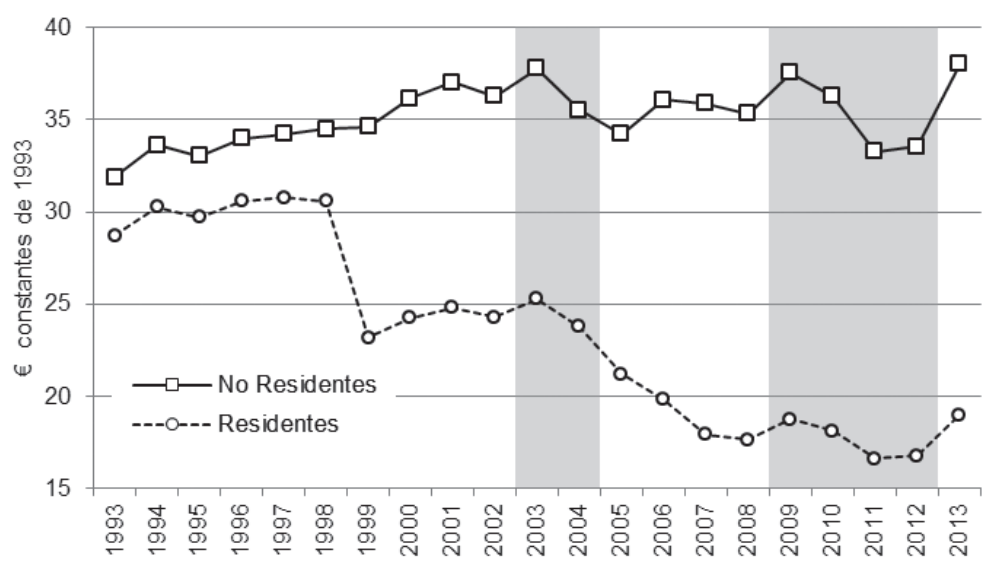

Fuente: Elaboración propia en base a Ministerio de Fomento (2008) e ISTAC (ver nota al pie $\mathrm{N}^{\circ}$ 9).

continuada de Islas Airways en el mercado interinsular. Los datos muestran que a priori dicho impacto ha sido mínimo en lo que respecta al precio medio que han pagado los residentes por un vuelo interinsular. Entre 2007 y 2012 ese precio medio se rebajó, en términos reales, en poco más de un euro. Es más, incluso se observa un leve repunte entre 2008 y 2009, claramente relacionado con el notable aumento en los precios del combustible observado en 2008, que ambas compañías repercutieron en las tarifas aplicadas. El descenso que se verifica posteriormente, especialmente entre 2010 y 2011, deriva en parte de la agresiva estrategia adoptada por Islas Airways para intentar incrementar su cuota de mercado, lo que propició que ambas compañías terminaran estableciendo de forma permanente un amplio abanico de tarifas promocionales que anteriormente estaban circunscritas a fechas muy concretas. Sin embargo, esa estrategia no podía prolongarse indefinidamente, de tal forma que incluso antes de la desaparición de Islas Airways las tarifas medias comenzaran a incrementarse, aumentando un 12,7\% entre 2011 y 2012 (Ministerio de Fomento, 2013a). Esta tendencia alcista ha continuado durante el primer semestre de 2013, donde el aumento del precio medio se ha cifrado en un 5,4\% (Ministerio de
Fomento, 2013b), lo que confirma que este incremento puede asociarse a la ausencia de competencia. Por tanto, la presencia de Islas Airways fue clave a partir de 2007 para el mantenimiento de los precios medios más bajos por trayecto de los últimos veinte años. La reducción de las ofertas promocionales de Binter Canarias desde finales desde 2012, el acusado descenso de la demanda aérea ${ }^{5}$ y el repunte de la demanda de transporte marítimo observado desde principios de 2013 en algunas líneas en las que el desplazamiento en barco es relativamente competitivo con el avión, caso de la relación Santa Cruz de La

\footnotetext{
5 Ya con Islas Airways fuera del mercado, el número de pasajeros interinsulares registrado en 2013 no alcanzó los 2,5 millones, lo que supuso una pérdida de 375.000 pasajeros respecto al año 2012, retrotrayendo la demanda a los valores del año 2003. Aunque la ausencia de competencia ha influido en el retroceso de la demanda, el factor más relevante para explicar ese descenso es la intensidad de la crisis económica que afecta al archipiélago. Recordemos que en Canarias, según datos de la Encuesta de Población Activa del Instituto Nacional de Estadística (INE), la tasa de paro se elevaba al $34,8 \%$ en el tercer trimestre de 2013, nueve puntos por encima de la media nacional y 24 puntos más que la registrada en Canarias durante el segundo trimestre de 2007.
} 
Palma-Los Cristianos ${ }^{6}$, parecen apuntar en la dirección del aumento de las tarifas aéreas.

\section{El comportamiento de la demanda y la difusión social del modo aéreo}

En un contexto caracterizado por el incremento de la oferta de frecuencias y plazas y el descenso en las tarificadas practicadas, no resulta extraño el notable aumento de la demanda verificado en el mercado interinsular. Esta alcanzó un máximo histórico en el año 2007, cuando se contabilizaron 3,5 millones de pasajeros. Ello suponía prácticamente duplicar las cifras del año 1997, lo que evidenciaba un acelerado ritmo de crecimiento durante esa década. Por otro lado, y dado que el descenso real en el precio medio de los trayectos interinsulares para los residentes se prolongó desde 1998 hasta 2011, cabría esperar que hubiera aumentado el número de personas que pueden acceder al modo aéreo.

Aunque existen algunas discrepancias puntuales entre los datos y los obtenidos a partir de las respuestas dadas a las preguntas al gobierno planteadas por distintos senadores, que maneja el Instituto de Estadística de Canarias (ISTAC) ${ }^{7}$, puede afirmarse que en torno al $85 \%$ del tráfico interinsular es imputable a pasajeros residentes en las islas. Así, en el año 2012, 2,4 de los 2,8 millones de viajes interinsulares registrados tuvieron de-

\footnotetext{
6 El tráfico de pasajeros en esta ruta aumentó en un $50,6 \%$ durante el año 2013, coincidiendo una reducción del $17,7 \%$ en la conexión aérea La Palma-Tenerife Norte.

7 Esas discrepancias propician que tengamos una notable incertidumbre sobre la fiabilidad de los datos relativos a los años 2011 y 2012. Es posible que las divergencias observadas se deban a la suspensión de los pagos a Islas Airways por parte del Ministerio de Fomento tras la denuncia de fraude recibida por la Dirección General de Aviación Civil. Probablemente ello haya dado lugar a que una parte de los pasajeros residentes no se contabilizaran como tal en 2011 y se incluyeran en las estadísticas de 2012, pero es una mera hipótesis sin confirmar. Asimismo, los seis meses con que cuentan las compañías aéreas para solicitar al Ministerio de Fomento la compensación económica derivada de la bonificación que aplican a las tarifas de los residentes, también propicia demoras a la hora de conocer los datos reales de cada año.
}

recho a la bonificación por residencia (SERC, 2013). Si tenemos en cuenta que en ese año prácticamente dos millones de residentes en Canarias podían acceder a la bonificación ${ }^{8}$, obtenemos que los habitantes de las islas habrían realizado 1,2 desplazamientos interinsulares por persona y año, muy lejos de los valores que se obtienen en territorios periféricos y extremadamente dependientes del transporte aéreo como la región Finnmark en el norte de Noruega, donde en 2009 se registraron 5,4 desplazamientos interiores por persona y año (Halpern \& Bråthen, 2011, 1.146). Esta cifra es muy llamativa, pues contraría una percepción ampliamente difundida por una buena parte de los políticos del archipiélago, reproducida por los medios de comunicación y profundamente arraigada en el imaginario colectivo de la sociedad canaria: la de que existe una elevada movilidad aérea interinsular de la que participa una amplia mayoría de la población residente.

Podemos desmitificar aún más esa imagen si tenemos en cuenta que cada viaje no es realizado por un pasajero diferente, por un individuo distinto, sino que cada persona puede realizar varios desplazamientos a lo largo del año. Por tanto, lo relevante en lo que concierne al estudio de la difusión social del modo aéreo es conocer el número de individuos que se benefician de las ayudas, si bien ello no es sencillo debido a la opacidad estadística que existe al respecto. Según se desprende de una intervención parlamentaria de la ministra de Fomento, Ana Pastor (DSCD, 2012), los 2,1 millones de viajes bonificados durante el año 2011 fueron efectuados únicamente por 479.712 personas, es decir, el $24 \%$ de la población residente en el archipiélago con derecho a descuento. Por tanto, el 76\% residentes en las islas no realizó ningún desplazamiento de esas características y entre el $24 \%$ restante tuvieron un peso significativo los residentes en las islas periféricas (ver nota 4), para quienes estos desplazamientos pueden ser muy relevantes para resolver los

\footnotetext{
8 Hasta el 1 de abril de 2013, únicamente los residentes de nacionalidad comunitaria, noruega, suiza e islandesa tenían derecho a la bonificación por residencia, por lo que quedaban excluidos todos aquellos residentes que fueran nacionales de terceros países.
} 
Cuadro $\mathrm{N}^{\circ} 4$

Beneficiarios residentes según $n^{\circ}$ de viajes realizados y simulación de ayudas recibidas en 2011

\begin{tabular}{|c|c|c|c|c|c|c|c|}
\hline \multicolumn{3}{|c|}{ Beneficiarios } & \multicolumn{5}{|c|}{ Distribución ayudas (valores simulados) } \\
\hline $\begin{array}{l}\text { Viajes (ida y } \\
\text { vuelta) }\end{array}$ & Personas & $\%$ & $\begin{array}{c}N^{\circ} \text { medio } \\
\text { viajes }(\mathrm{i} / \mathrm{v})\end{array}$ & Trayectos & $\begin{array}{l}\text { Ayuda } \\
\text { recibida }\end{array}$ & $\%$ & $\begin{array}{l}\text { Ayuda media } \\
\text { por beneficiario }\end{array}$ \\
\hline$<10$ & 456.621 & 95,2 & 1,5 & 1.369 .863 & 38.876 .712 & 64,0 & 85,1 \\
\hline $10-20$ & 16.436 & 3,4 & 11 & 361.592 & 10.261 .981 & 16,9 & 624,4 \\
\hline $21-30$ & 4.846 & 1,0 & 24 & 232.608 & 6.601 .415 & 10,9 & $1.362,2$ \\
\hline $31-100$ & 1.138 & 0,2 & 42 & 95.592 & 2.712 .901 & 4,5 & $2.383,9$ \\
\hline $51-100$ & 638 & 0,1 & 55 & 70.180 & 1.991 .708 & 3,3 & $3.121,8$ \\
\hline $101-150$ & 24 & 0,0 & 140 & 6.720 & 190.714 & 0,3 & $7.946,4$ \\
\hline$>150$ & 9 & 0,0 & 275 & 4.950 & 140.481 & 0,2 & $15.609,0$ \\
\hline TOTAL & 479.712 & 100 & 2,2 & 2.141 .505 & 60.775 .912 & 100 & 100,0 \\
\hline \multicolumn{8}{|c|}{ Datos de control (valores reales en redonda, simulados en cursiva) } \\
\hline$>30$ & 1.809 & 0,4 & 49,0 & 177.442 & 5.035 .804 & 8,3 & $2.783,8$ \\
\hline$>100$ & 33 & 0,0 & 176,8 & 11.670 & 331.195 & 0,5 & $10.036,2$ \\
\hline
\end{tabular}

FUENTE: DSS (2012), DSCD (2012) e ISTAC (2013)

déficits asociados a una cierta infradotación de servicios públicos y privados observada en sus islas.

Solo conociendo la evolución en el tiempo del número de beneficiarios de la bonificación por residencia estaríamos en condiciones de evaluar si el abaratamiento de las tarifas ha incrementado el acceso al modo aéreo. Aunque ello puede considerarse una consecuencia lógica de la reducción del precio de los billetes, algunos estudios previos han mostrado que no siempre existe una relación causa-efecto directa entre ambas variables (CAA, 2006; Ramos Pérez, 2008). Lo que sí podemos avanzar con los datos que en este momento contamos es que una parte significativa de las ayudas destinadas a la bonificación de los viajes de los residentes insulares podría estar siendo acaparada por un segmento reducido de los beneficiarios que presentan un comportamiento hipermóvil. $Y$ es que a partir de la información ofrecida por la mencionada ministra de Fomento en su intervención parlamentaria hemos procedido a estratificar los residentes que realizan vuelos interinsulares, agrupándolos por intervalos según el número total de viajes anuales de ida y vuelta.
En el Cuadro $\mathrm{N}^{\circ} 4$ se observa que la inmensa mayoría de los beneficiarios de la bonificación por residencia se han desplazado durante el año 2011 menos de diez veces al año, existiendo únicamente un $4,8 \%$ que se sitúa por encima de dicho umbral. Sin embargo, al realizar un ejercicio de simulación de la distribución de las ayudas a cada uno de los intervalos previamente definidos, se puede comprobar cómo ese pequeño porcentaje concentra una parte muy significativa de la bonificación por residencia.

Para efectuar la simulación partimos del número de trayectos aéreos efectuados por los residentes en 2011 según el ISTAC ${ }^{9}$ y la Dirección General de Aviación Civil (2.141.773) y del montante total destinado por el Ministerio de Fomento a la bonificación por residencia durante ese ejercicio (60.778.309 de euros). A partir de ambas cifras se obtiene el valor medio alcanzado por

\footnotetext{
9 Series anuales de subvenciones al transporte aéreo. Canarias. 2005-2012. Disponible en Internet: http://www.gobiernodecanarias.org/istac/jaxi-istac/ menu.do? uripub=urn:uuid: $9309 \mathrm{e} 1 \mathrm{~d} 4-\mathrm{a} 85 \mathrm{c}-40 \mathrm{~cd}-$ 8ce1-86f79d3f0c91
} 
la subvención en ese año (28,38 euros), con lo que únicamente nos restaría por saber el número medio de viajes de ida y vuelta que correspondería a cada intervalo. Dicha información no se suministra oficialmente, pero en otra intervención más reciente (DSS, 2012) la propia ministra de Fomento ha indicado que se han destinado cinco millones de euros para financiar los desplazamientos de los beneficiarios que hicieron más de 30 viajes de ida y vuelta, así como 330.000 para sufragar la bonificación de los que efectuaron más de 100 viajes.

Con estos datos podemos asignar a cada intervalo un número medio de viajes -es decir, una especie de marca de clase-, que sea coherente con todos los valores señalados, reduciendo notablemente el margen de error de la simulación, cuyos resultados se presentan en la parte derecha del cuadro $\mathrm{n}^{\circ}$ 4. Aunque el grueso de las ayudas para la bonificación por residencia se transfiere al grupo de personas que realiza menos de diez viajes, lo verdaderamente Ilamativo es que menos del $5 \%$ de los beneficiarios estarían acaparando el $36 \%$ de las ayudas $y$, por tanto, de los trayectos volados. O que el $0,4 \%$ de los residentes beneficiados concentre el $8,3 \%$ del subsidio total otorgado por el Ministerio de Fomento. En ese sentido, los 85 euros que recibe quien apenas se desplaza en una ocasión a otra isla contrastan con los miles de euros que obtienen aquellos que lo hacen en decenas de ocasiones. Aunque únicamente se trata de un ejercicio de simulación ${ }^{10}$, y habría que saber si las personas que presentan una elevada movilidad interinsular lo hacen forzadas por motivos de salud o únicamente personales, ello plantea una duda razonable sobre la equidad en la asignación de la bonificación por residencia, pero también sobre la difusión social del modo aéreo entre el conjunto de la población gracias al descenso de las tarifas.

\footnotetext{
${ }^{10}$ Conviene señalar que pequeñas variaciones en la marca de clase escogida para los intervalos con un menor número medio de viajes pueden generar cambios sustanciales en la asignación de la ayuda recibida simulada. En cualquier caso, subrayamos que las marcas de clase escogidas permiten obtener unos resultados coherentes con todos los datos reales conocidos, lo que apuntala la validez de la simulación.
}

\section{La relación entre oferta y demanda: las variaciones en el coeficiente de ocupación}

Aunque la entrada de Islas Airways en el mercado interinsular supuso una expansión general del sistema (oferta de frecuencias y plazas, incremento de la demanda), solo lastrada por los efectos de la crisis económica y financiera, también tuvo otra consecuencia relevante: la reducción constante de los niveles de ocupación de los aviones en aquellas rutas en las que existía competencia entre ambas compañías.

En el año 2002 Binter Canarias registraba un coeficiente de ocupación para el conjunto del sistema interinsular superior al $74 \%$, si bien había descendido cuatro puntos desde 1999 (Hernández Luis, 2010). Estos altos niveles de ocupación han sido una característica constante del sistema desde los años ochenta, llegando a superar el $80 \%$ a finales de los años ochenta, lo que dificultaba la obtención de plazas libres en algunas rutas y horas. La creación de Binter Canarias en 1988 pretendía no solo implantar un modelo de explotación que limitase las notables pérdidas que experimentaba Iberia en esas rutas, sino ofrecer unos servicios más adecuados a las necesidades de los desplazamientos interinsulares, lo que suponía rebajar dichos índices de ocupación. Ello se consigue desde 1997, fecha en la que Binter Canarias obtiene por primera vez beneficios económicos con un coeficiente de ocupación medio del $69,1 \%$. Pero esa cifra queda muy lejos del $60,7 \%$ de ocupación media que registró el mercado interinsular en el año 2003 (Hernández Luis, 2010): la entrada de Islas Airways redujo en menos de un año el coeficiente de ocupación en casi 14 puntos. Con el paso del tiempo las cifras se recuperaron ligeramente, pues Binter procedió a un ajuste de su oferta que desde 2005 permitió situar la ocupación media anual en torno al $65 \%$, valor que en 2011, último año completo de operaciones de Islas Airways, alcanzó el $66 \%$.

Cómo es lógico estos valores medios de ocupación esconden notables diferencias entre unas rutas y otras y entre diferentes épocas del año. En el año 2002 las seis rutas a las que Islas Airways prestará más atención 
Cuadro $\mathrm{N}^{\circ} 5$

Evolución del coeficiente de ocupación en las rutas interinsulares

\begin{tabular}{|c|c|c|c|c|c|c|c|c|c|}
\hline Rutas & 1999 & 2002 & 2007 & 2011 & 2012 & 2013 & $\begin{array}{c}\text { Marzo } \\
2012 \\
\end{array}$ & \begin{tabular}{|c|} 
Marzo \\
2013 \\
\end{tabular} & Diferencia \\
\hline $\begin{array}{l}\text { Tenerife Norte Gran Can } \\
\text { (TFN) } \quad \text { (LPA) }\end{array}$ & 68,9 & 72,4 & 67,2 & 65,2 & 67,0 & 68,4 & 69,1 & 70,8 & 1,7 \\
\hline $\begin{array}{l}\text { Tenerife Norte La Palma } \\
\begin{array}{ll}\text { (TFN) } & \text { (SPC) }\end{array}\end{array}$ & 83,3 & 81,7 & 63,5 & 63,6 & 66,9 & 72,5 & 57,1 & 69,3 & 12,2 \\
\hline $\begin{array}{ll}\text { Gran Canaria } & \text { Lanzarote } \\
\text { (LPA) } & \text { (ACE) }\end{array}$ & 81,5 & 80,7 & 62,8 & 70,6 & 73,6 & 72,8 & 64,5 & 73,8 & 9,3 \\
\hline $\begin{array}{ll}\text { Gran Canaria } & \text { Fuerteventura } \\
\text { (LPA) } & \text { (FUE) }\end{array}$ & 79,4 & 77,3 & 68,0 & 69,7 & 71,2 & 70,5 & 66,6 & 66,8 & 0,2 \\
\hline $\begin{array}{l}\text { Tenerife Norte Lanzarote } \\
\text { (TFN) }\end{array}$ & 82,5 & 77,7 & 60,5 & 75,1 & 70,0 & 77,4 & 66,6 & 76,0 & 9,4 \\
\hline 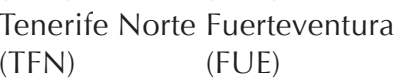 & 79,7 & 76,4 & 61,1 & 66,0 & 64,4 & 69,9 & 54,9 & 69,3 & 14,4 \\
\hline $\begin{array}{l}\text { Tenerife Norte El Hierro } \\
\begin{array}{ll}(\mathrm{TFN}) & \text { (VDE) }\end{array}\end{array}$ & 74,8 & 70,4 & 68,0 & 64,3 & 62,7 & 62,2 & 57,3 & 67,2 & 9 \\
\hline $\begin{array}{ll}\text { Gran Canaria } & \text { La Palma } \\
\text { (LPA) } & \text { (SPC) }\end{array}$ & 73,6 & 67,7 & 91,8 & 62,6 & 60,6 & 68,1 & 52,9 & 70,9 & 18 \\
\hline $\begin{array}{ll}\text { Gran Canaria } & \text { Tenerife Sur } \\
(\text { LPA }) & \text { (TFS) }\end{array}$ & -- & 79,5 & 58,5 & 53,6 & 55,2 & 50,5 & 47,9 & 53,4 & 5,6 \\
\hline $\begin{array}{l}\text { Tenerife Norte La Gomera } \\
\begin{array}{ll}\text { (TFN) } & \text { (GMZ) }\end{array}\end{array}$ & 28,6 & 44,4 & 63,0 & 47,1 & 24,6 & 24,3 & 21,3 & 25,5 & 4, \\
\hline $\begin{array}{ll}\text { Gran Canaria } & \text { El Hierro } \\
(\text { LPA) } & \text { (VDE) }\end{array}$ & 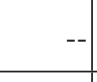 & 75,0 & 61,9 & 55,0 & 37,1 & 34,3 & 36,6 & 34,7 & $-1,9$ \\
\hline Media sistema & 78,5 & 74,6 & 64,5 & 66,0 & 67,1 & 68,6 & 61,9 & 68,7 & 6,8 \\
\hline
\end{tabular}

FUENTE: Hernández Luis (2010) para los años 1999, 2002 y 2007. Cálculos propios a partir del servidor estadístico de AENA y la base de datos OAG para los años 2011, 2012 y 2013.

durante sus años de actividad son las que presentan coeficientes de ocupación más elevados, superándose incluso el $80 \%$ en las relaciones La Palma-Tenerife Norte y LanzaroteGran Canaria (Cuadro № 5). En el año 2007 ya son visibles los efectos de la competencia en todas esas rutas, en las que la bajada de la ocupación media ha sido en general superior a la experimentada en el conjunto del mercado interinsular, con descensos que en algunos casos se sitúan entre los 15 y los 18 puntos.

Sin embargo, conviene señalar que estos coeficientes de ocupación eran relativamente bajos para el contexto del mercado europeo de transporte aéreo, donde se observa una tendencia clara al aumento de los mismos debido a la acentuación de la competencia y la reducción de los márgenes de beneficio en multitud de rutas. La imagen recurrente de aviones efectuando trayectos interinsulares con un escaso número de pasajeros, no solo indicaba una notable pérdida de eficiencia energética y ambiental de la red, sino la existencia de un riesgo evidente de inviabilidad económica de las operaciones.

A partir del coeficiente de ocupación no es posible inferir la rentabilidad de una ruta, ya que debido a la relativa invariabilidad de los costes fijos respecto al volumen de la demanda lo relevante es el ingreso medio por pasajero. Pero no cabe duda de que al prolongar en el tiempo niveles de ocupación bajos, ambas compañías redujeron sus márgenes de rentabilidad. En el caso de Islas Airways ese margen simplemente parece haber desaparecido. Por ello, el sustancial aumento de su cuota de mercado solo fue posible gracias a la drástica reducción en los ingresos por pasajero transportado, lo que previsiblemente le impedía cubrir los costes 
operativos, incurriendo en continuos déficits económicos de explotación ${ }^{11}$.

Tras la desaparición de Islas Airways, la recuperación de la ocupación ha sido casi instantánea, ya que Binter Canarias se ha limitado a mantener su programación de vuelos, introduciendo incluso ligeras reducciones a partir de enero de 2013. En noviembre de 2012, primer mes completo sin la presencia de Islas Airways, la ocupación media de la red interinsular ya se situaba en el $70,3 \%$, cinco puntos superior a la registrada en el mes de septiembre. Como no podía ser de otra manera, la recuperación de los índices de ocupación fue superior a la media en la mayor parte de las rutas en las que había existido competencia, retornando los guarismos del $70 \%$ (cuadro $n^{\circ}$ 5). Para tener una idea certera de la magnitud de los cambios compramos los datos de marzo de 2013 con los de marzo de 2012, comprobando que ha tenido lugar un aumento de siete puntos porcentuales en el conjunto del sistema, con incrementos superiores en algunas de las rutas que habían contado con mayor presencia de Islas Airways.

A partir de 2013, la progresiva incorporación del nuevo operador Canary Fly, en algunas de las rutas que habían contado con mayor presencia de Islas Airways, comienza a tener algún impacto en la evolución de esta variable. Aunque no ha frenado el aumento del coeficiente de ocupación en el conjunto del sistema, que pasa de una media anual de $68,6 \%$ en 2013 a $69,8 \%$ en 2014 , sí que ha posibilitado una rebaja de más de tres puntos porcentuales entre ambas fechas en las dos rutas donde tiene una mayor presencia: Tenerife Norte-La Palma (de $72,5 \%$ a $69,2 \%$ ) y Gran Canaria-Lanzarote (de $72,8 \%$ a $69 \%$ ). Por el momento, la reacción de Binter se ha limitado a reducir ligeramente su ofer-

\footnotetext{
11 Por otro lado, la denuncia presentada por Binter Canarias ante el Ministerio de Fomento, acusando a Islas Airways de un presunto fraude en la gestión de los billetes con derecho a bonificación de residencia, implicó la suspensión de los pagos que periódicamente se realizaban a la compañía para compensar los descuentos aplicados directamente a los residentes canarios. Sin duda ello acentuó la falta de liquidez de Islas Airways y posiblemente acelerara el final de sus operaciones.
}

ta, por lo que ha incrementado aún más su ocupación, hasta superar el $74 \%$ en ambas conexiones.

\section{La funcionalidad horaria en un contexto de competencia}

La adecuada distribución horaria de las frecuencias puede considerarse un parámetro clave a la hora de evaluar la calidad de los servicios aéreos en territorios que presentan una notable dependencia de los mismos. En el caso de los desplazamientos interinsulares destaca la elevada proporción de los viajes pendulares diarios (Hernández Luis, 2010). Ello es más relevante en el caso de los residentes en las islas periféricas cuyo traslado a las islas centrales viene motivado por la necesidad de llevar a cabo gestiones de tipo administrativo, comercial o sanitario (AENA, 2004) que en multitud de ocasiones pueden solventarse en algunas horas. Por ello, la programación de los vuelos debería permitir retornos en el día con tiempos de estancia en destino suficientes para resolver esas gestiones. La OSP que afecta los servicios interinsulares prevé esta circunstancia, estableciendo en seis de las trece rutas un tiempo mínimo de estancia en destino de ocho horas, que en otras tres se reduce a siete horas.

Siguiendo la metodología diseñada por Hernández Luis (1994) y partiendo de la programación horaria de las frecuencias, es posible analizar la evolución de los tiempos de estancia en destino para cada sentido de las diferentes rutas interinsulares. Si nos centramos en las siete principales rutas que conectan las islas centrales y periféricas ${ }^{12}$ y realizamos un análisis de conjunto, se observa como entre 2000 y 2008 el tiempo en destino aumentó de forma generalizada, si bien el sentido isla periférica-isla central resultó ligeramente más beneficiado (Figura $N^{\circ} 4$ ). Es decir, los residentes en las islas periféricas del archipiélago ganaron por término medio más de una hora de tiempo de estancia en

\footnotetext{
12 Dichas rutas son La Palma - Tenerife Norte, La Palma Gran Canaria, Lanzarote - Gran Canaria, Lanzarote Tenerife Norte, Fuerteventura - Gran Canaria, Fuerteventura - Tenerife Norte y El Hierro - Tenerife Norte.
} 
Figura $\mathrm{N}^{\circ} 4$

Cambios en la funcionalidad según tipo de ruta (mes febrero)

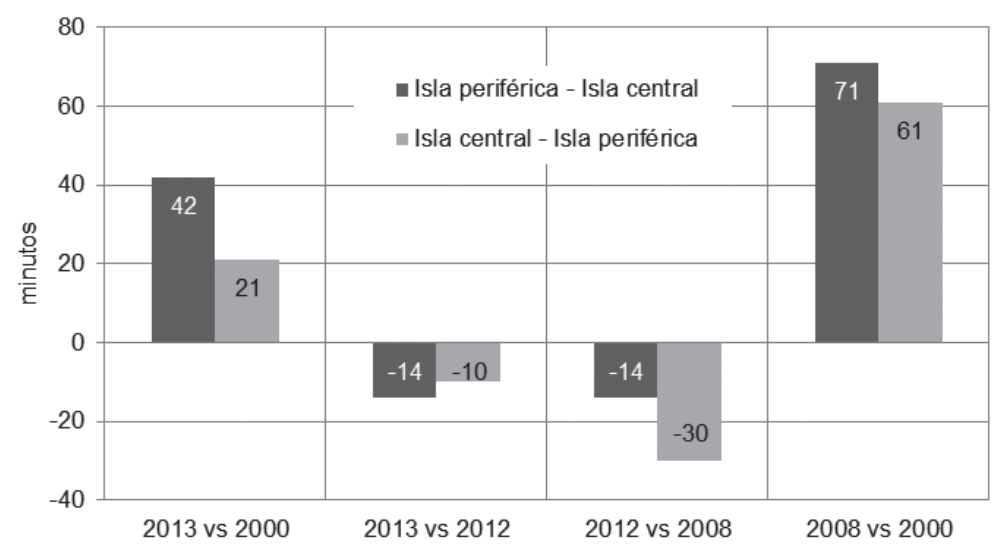

FUENTE: Elaboración propia a partir de la programación horaria de las compañías.

las islas centrales para sus desplazamientos pendulares. En algunas relaciones, como La Palma-Gran Canaria o Fuerteventura-Tenerife norte los aumentos superaron las dos horas y permitieron superar holgadamente las siete horas de estancia en destino que determina la OSP para ambas rutas. En otras relaciones, como La Palma-Tenerife norte o LanzaroteGran Canaria la programación de los vuelos permitía en febrero de 2008 superar ampliamente las diez horas de estancia máxima en destino para viajes pendulares como los descritos. Sin duda, la irrupción de Islas Airways en el mercado interinsular influyó en esta mejora de la funcionalidad horaria, pues intentó incrementar su demanda programando algunos de sus vuelos en franjas horarias que precisamente permitían ampliar el tiempo de estancia en destino.

La funcionalidad horaria alcanzaba su máximo histórico en el sistema interinsular en el año 2008. Posteriormente, el impacto de la crisis económica y financiera va a propiciar una reducción de las frecuencias ofertadas como consecuencia del descenso de la demanda. Ello ha supuesto una merma de los tiempos máximos de estancia en destino, que durante el periodo 2008-2012 es achacable a los reajustes que realizan ambas compañías y desde octubre de 2012 es el resultado de la nueva estrategia de Binter Canarias tras la desaparición de Islas Airways. Sin embargo, el balance del periodo 2000-2013 continúa siendo claramente positivo para los usuarios del transporte interinsular, especialmente para los residentes en las islas periféricas. En febrero de 2013 se superaban en todas las rutas y sentidos los tiempos mínimos que marca la declaración de OSP salvo en las relaciones Lanzarote-Tenerife norte y El Hierro-Tenerife norte, aunque en esta última nunca se ha cumplido el valor estipulado, debido en parte al limitado horario de apertura del aeropuerto herreño.

\section{El impacto de la competencia en las relaciones laborales}

El incremento de la competencia en un mercado aéreo no solo implica cambios en la estrategia operativa de las compañías o una transformación de su política tarifaria. El reparto de los ingresos entre más de un operador puede contraer significativamente el margen de beneficios, lo que conlleva de forma casi inmediata un intento de reducción de los costes laborales por parte de las compañías. Existen ya en la literatura algunos análisis que muestran una cierta diversidad en el comportamiento adoptado por compañías a la hora de reducir sus costes laborales como consecuencia del incremento de la competencia. Esa diversidad está en parte relacionada con la tradición capitalista, liberal o cooperativa, 
dominante en el país en el que se asienta la aerolínea. Donde prima la orientación liberal, los despidos masivos y la reducción de beneficios laborales han dominado, como ha ocurrido en British Airways. Donde existe una tradición cooperativa y de coordinación entre gestores empresariales y trabajadores, la reducción de costes ha venido asociado a una mejora de la productividad por trabajador y la moderación salarial, que ha afectado con mayor intensidad a los ejecutivos, como en el caso de la escandinava SAS (Bamber et al., 2009). En el caso de España, que no encaja exactamente en ninguna de las dos tradiciones capitalistas señaladas, se aprecia durante los últimos años una clara tendencia a la adopción de medidas propias de una concepción liberal.

La simple entrada de Islas Airways en el mercado interinsular, supuso una presión sobre los salarios de Binter Canarias, pues la nueva compañía estableció unas retribuciones fijas sustancialmente inferiores a las existentes hasta ese momento, tanto para los tripulantes de cabina de pasajeros (TCP) como para los pilotos. Aunque es complejo establecer comparaciones a partir de las tablas salariales de los convenios colectivos, puede realizarse una aproximación a los cambios ocurridos considerando únicamente las retribuciones mensuales fijas ${ }^{13}$ que corresponderían a cuatro perfiles laborales concretos: un comandante de máximo nivel con doce años de antigüedad, un segundo piloto recién entrado en la compañía, un TCP de máximo nivel con nueve años de antigüedad y un TCP recién incorporado.

Como puede observarse en el cuadro $\mathrm{n}^{\circ} 6$, en todos los casos considerados los salarios de Islas Airways presentan valores inferiores a los estipulados en el convenio colectivo de Binter Canarias. Como era de esperar, las mayores diferencias se producen en el caso de los pilotos, ya que pierden más del $50 \%$ de su salario, mientras en el caso de los TCP las rebajas de sueldo no alcanzan el

\footnotetext{
13 Todos los valores presentados se incrementan una vez contabilizada la parte variable del salario, pero son sumamente esclarecedores de los cambios ocurridos, dado que los ingresos asociados a la parte variable no han experimentado mejora alguna.
}

30\%. Paradójicamente, esta nueva estructura salarial reduce a la mitad las desigualdades de ingreso entre los trabajadores que se encuentran en los extremos de la misma. Sin embargo, ello se hace a costa de colocar a Ios TCP por debajo del umbral de los 1.000 euros mensuales brutos y a los pilotos que inician su carrera profesional ligeramente por encima. Además, la brecha salarial entre los distintos escalones de cada grupo no se redujo, sino todo lo contrario, como se desprende de las ratios calculadas para los dos tipos de pilotos y TCP, siendo especialmente significativo en el caso de los primeros. Como recortes similares han tenido lugar en los trabajadores de tierra, tanto en los que trabajan de cara al público como en la recogida de equipajes, es evidente que la nivelación salarial se ha efectuado a la baja, restando por saber lo que ocurrió con los puestos directivos de la nueva aerolínea.

La reacción de los propietarios de Binter Canarias no se hizo esperar, adoptando una estrategia que no era desconocida en el sector. Cuando el nivel de sindicación de los trabajadores de una aerolínea es elevado, como era el caso, los gestores han ingeniado una fórmula ya recurrente para sortear los convenios colectivos en vigor, anular el poder de negociación sindical y presionar a la baja sobre las condiciones laborales de la plantiIla: crear una o varias filiales a las que se va traspasando la producción hasta que dicha filial termina haciéndose con la totalidad de la misma. La matriz se convierte en una empresa hueca, sin apenas trabajadores, pero que normalmente interesa mantener activa para conservar su marca. Por supuesto, las condiciones laborales de partida y el convenio laboral que llegue firmarse en estas filiales rebajarán notablemente las remuneraciones y derechos sociales vigentes en la compañía matriz.

Esta estrategia motiva que Binter Canarias compre Naysa en el año 2007, a la que transfieren paulatinamente sus aviones y personal. Como puede observarse en el Cuadro $\mathrm{N}^{\circ} 6$, las remuneraciones que ofrecía Naysa eran similares a las recogidas en el convenio colectivo de Islas, lo que para Binter Canarias suponía una notable reducción de los costes laborales. Para acentuar esta estrategia, Binter Canarias crea una nueva compañía durante 
Cuadro $\mathrm{N}^{\circ} 6$

Diferencias de salario mensual fijo entre compañías aéreas según categorías

\begin{tabular}{|c|c|c|c|c|c|c|c|c|}
\hline $\begin{array}{l}\text { Tripulantes cabina } \\
\text { pasajeros }\end{array}$ & $\begin{array}{l}\text { Binter } \\
(\mathrm{NT})\end{array}$ & $\begin{array}{l}\text { Islas } \\
\text { (FW) }\end{array}$ & $\begin{array}{l}\text { Naysa } \\
(\mathrm{ZN})\end{array}$ & $\begin{array}{l}\text { Canair } \\
\text { (RSC) }\end{array}$ & NT vs FW & $\%$ & $\begin{array}{l}\text { NT vs } \\
\text { RSC }\end{array}$ & $\%$ \\
\hline $\begin{array}{l}\text { Jefa cabina máximo } \\
\text { nivel } 9 \text { años (a) }\end{array}$ & $2.114,46$ & $1.494,14$ & $1.481,75$ & $1.396,67$ & $-620,31$ & $-29,3$ & $-717,79$ & $-33,9$ \\
\hline $\begin{array}{l}\text { TCP recién contratado } \\
\text { (b) }\end{array}$ & $1.324,02$ & $1.198,65$ & $1.035,31$ & 835,36 & $-125,37$ & $-9,5$ & $-488,66$ & $-36,9$ \\
\hline Pilotos & $\begin{array}{l}\text { Binter } \\
(\mathrm{NT})\end{array}$ & $\begin{array}{l}\text { Islas } \\
(\text { FW) }\end{array}$ & $\begin{array}{l}\text { Naysa } \\
(\mathrm{ZN})\end{array}$ & $\begin{array}{l}\text { Canair } \\
\text { (RSC) }\end{array}$ & NT vs FW & $\%$ & $\begin{array}{l}\text { NT vs } \\
\text { RSC }\end{array}$ & $\%$ \\
\hline $\begin{array}{l}\text { Comandante máximo } \\
\text { nivel } 12 \text { años (c) }\end{array}$ & $10.323,98$ & $4.526,80$ & $5.097,43$ & $3.749,99$ & $-5.797,19$ & & $-6.573,99$ & $-63,7$ \\
\hline $\begin{array}{l}2^{\circ} \text { piloto recién } \\
\text { contratado }(\mathrm{d})\end{array}$ & $4.256,32$ & $2.273,64$ & $1.785,25$ & $1.041,66$ & $-1.982,68$ & $-46,6$ & $-3.214,66$ & $-75,5$ \\
\hline Desigualdades: (c) vs (b) & 7,8 & 3,8 & 4,9 & 4,5 & & & & \\
\hline (b) vs (a) & 1,6 & 1,2 & 1,4 & 1,7 & & & & \\
\hline (d) vs (c) & 2,4 & 2,0 & 2,9 & 3,6 & & & & \\
\hline
\end{tabular}

Nota: Los valores de los convenios han sido ajustados a euros de agosto de 2013.

Fuente: BOC (1999, 2006, 2007a, 2007b, 2008 y 2013).

el año 2011, Canarias Airlines - Canair, que recorta las remuneraciones de los pilotos respecto a las que ofrecía Naysa y mantiene en una cuantía ligeramente inferior las de los TCPs. Además, en este caso, el convenio colectivo ya desvincula la revisión salarial de los cambios en el IPC, explicitando que únicamente en caso de resultados económicos positivos, a partir de 2015 se incrementarán las retribuciones un 1\%. Ello permite entender por qué la producción actual de Binter Canarias dentro del grupo es residual, repartiéndose Naysa y Canair el 96,6\% de los pasajeros interinsulares transportados durante septiembre de 2013.

Sin embargo, esta situación puede variar a medio plazo, ya que en 2014 la dirección de Binter Canarias consigue modificar el convenio colectivo por el que se regía la matriz (BOC, 2014), fijando unas remuneraciones claramente inferiores a las de su subsidiaria Canarias Airlines. En ese sentido, no es descartable que se proceda a un nuevo trasvase de la producción, aunque ahora en sentido inverso, desde las filiales creadas a la matriz Binter Canarias. El hecho de que la nueva compañía concurrente, Canary Fly, también practique una política de salarios bajos, con retribuciones fijas según convenio inferiores a las de Canarias Airlines y Naysa (BOP, 2014), refuerza esta hipótesis: Binter no dudará en concentrar sus operaciones en aquella compañía que le ofrezca unos menores costes operativos, y ello hoy por hoy sucede en la empresa matriz.

\section{Conclusiones}

La existencia de unas tarifas máximas y de una oferta mínima de plazas y frecuencias en el mercado interinsular, derivadas de la declaración de OSP, minimiza el impacto potencial de la competencia. El incremento de la proporción de tarifas promocionales y el aumento de la oferta son los principales resultados de este amplio periodo de concurrencia analizado. Aunque a priori ello tuvo un impacto positivo para los pasajeros, es evidente que también propició impactos ne- 
gativos si analizamos el sistema de transporte aéreo desde una perspectiva integradora: los coeficientes de ocupación se han desplomado en la mayoría de las rutas, lo que ha terminado reduciendo los ingresos de las compañías y ha propiciado una carrera para la reducción de costes que ha afectado sobremanera a los trabajadores del sector. Además, la caída de la ocupación y del ingreso medio por pasajero, fruto de la multiplicación de tarifas promocionales, comprometió la rentabilidad de las operaciones, siendo uno más de los factores que determinaron la salida del mercado de Islas Airways.

En ese sentido es discutible afirmar que la concurrencia haya generado una maximización del bienestar, especialmente si tenemos en cuenta que la movilidad interinsular en avión continúa restringida a un segmento limitado de los residentes en el archipiélago. Por ello, el aumento de la demanda observado en el pasado podría haber sido fruto, más de la multiplicación de los viajes en avión de un grupo reducido de personas que de una difusión en el acceso al transporte aéreo entre amplias capas sociales. Así parecen confirmarlo las notables desigualdades detectadas en el uso del modo aéreo, tanto por lo limitado de la población residente que participa de la misma (24\%) como por la polarización en la distribución de los desplazamientos aéreos observada entre aquellos que viajaron en avión entre las islas durante 2011.

La constatación de esta realidad debería abrir el debate político sobre la reforma del modelo de bonificación al residente actualmente existente, al objeto de conseguir que las ayudas se destinen realmente a asegurar la movilidad aérea de quienes más lo necesitan. Estas ayudas no deben propiciar, como ocurre actualmente, una transferencia de rentas hacia quienes, como consecuencia de su mayor poder adquisitivo, realizan muchos más viajes en avión. Para ello, medidas como modular la bonificación en función de la renta o imponer un máximo anual de viajes interinsulares subvencionables, revisables en circunstancias de fuerza mayor, deben ser evaluadas para mejorar la efectividad del modelo.

El periodo de competencia analizado en este artículo no será el último del mercado interinsular canario. En diciembre de 2012 una nueva compañía, Canary Fly, inició su andadura en el mismo, operando las rutas que conectan Gran Canaria con Lanzarote y Fuerteventura. En noviembre de 2013 ha ampliado su red incorporando las relaciones Gran Canaria-Tenerife norte y Tenerife norteLa Palma, al tiempo que expande su oferta internacional centrada en el sur de Marruecos y Mauritania. En el segmento interinsular ha concentrado sus esfuerzos en las rutas con mayor tráfico en las que apuesta por una amplia variedad de tarifas promocionales que rebajan sustancialmente el coste del billete respecto a los máximos fijados por la OSP. Su cuota de mercado se situaba en el 7,5\% en enero de 2015, lo que evidencia que se trata de una experiencia mucho más modesta y comedida en su arranque que la de Islas Airways. En todo caso, lo que sí pone de manifiesto este intento es que el elevado tráfico que registran algunas rutas interinsulares va a continuar atrayendo a nuevos operadores, mostrando claramente el carácter espacialmente selectivo de la competencia.

\section{Referencias bibliográficas}

AENA. Aeropuerto de La Palma. Informe de resultados de encuestas año 2004. Semana tipo de marzo. Madrid: Aeropuertos Españoles y Navegación Aérea, 2004

AGUILERA KLINK, F. ¿Nacionalismo o subvencionalismo? Reflexiones sobre el modelo canario de victimismo económico. Revista Disenso, 2004, No 42, p. 36-37.

BAMBER, G.; GITTELL, J.; KOCHAN, T. \& VON NORDENFLYCHT, A. Up in the air: how airlines can improve performance by engaging their employees. Nueva York: Cornell University Press, 2009.

BEHNEN, T. Germany's changing airport infrastructure: the prospects for 'newcomer' airports attempting market entry. Journal of Transport Geography, 2004, Vol. 12, Nº 4, p. 277-286.

BETANCOR, O. y VIECENS, F. La competencia en el mercado español de transporte aéreo ( $2^{\circ}$ Informe del Observatorio de Transporte Aéreo de FEDEA). Madrid: Fundación de Estudios de Economía Aplicada, 2012. 
BOLETÍN OFICIAL DE CANARIAS (BOC). Dirección General de Trabajo. Anuncio por el que se hace pública la resolución de 7 de julio de 1999, que hace público el Convenio Colectivo de la empresa Binter Canarias y sus Tripulantes Pilotos. Boletín Oficial de Canarias, 1999, № 166 , p. 16.842-16.872.

BOLETíN OFICIAL DE CANARIAS (BOC). Dirección General de Trabajo. Anuncio por el que se hace pública la Resolución de 9 de febrero de 2006, relativo a registro, depósito y publicación del convenio colectivo Islas Airways, S.A. y su personal tripulante de Cabina de Pasajeros. Boletín Oficial de Canarias, 2006, No 43 , p. 4.353-4.386.

BOLETÍN OFICIAL DE CANARIAS (BOC). Dirección General de Trabajo. Anuncio por el que se hace pública la Resolución de 29 de marzo de 2007, relativa al registro, depósito y publicación del Acuerdo de la Comisión Negociadora del Convenio Colectivo de Navegación y Servicios Aéreos, S.A. (NAYSA). Boletín Oficial de Canarias, 2007a, № 86, p. 9.044-9.092.

BOLETÍN OFICIAL DE CANARIAS (BOC). Dirección General de Trabajo. Anuncio por el que se hace pública la Resolución de 14 de junio de 2007, relativa al registro, depósito y publicación del Acuerdo de la Comisión Negociadora del Convenio Colectivo Binter Canarias, S.A. y su personal de tierra y tripulantes de cabina de pasajeros. Boletín Oficial de Canarias, 2007b, № 129, p. 15.866-15.904.

BOLETÍN OFICIAL DE CANARIAS (BOC). Dirección General de Trabajo. Anuncio por el que se hace pública la Resolución de 25 de noviembre de 2008, que dispone el registro, depósito y publicación del II Convenio Colectivo de la Empresa Islas Airways, S.A. y sus tripulantes técnicos pilotos. Boletín Oficial de Canarias, 2008, № 248, p. 25.253-25.273.

BOLETÍN OFICIAL DE CANARIAS (BOC). Dirección General de Trabajo. Anuncio por el que se hace pública la Resolución de 1 de agosto de 2013, que dispone el registro, depósito y publicación del convenio colectivo de la empresa Canarias Airlines, Compañía de Aviación, S.L.U. y sus empleados: Tripulantes Técnicos Pilotos, Tripulantes de Cabina de Pasajeros y su Personal de Tierra (Canair).
Boletín Oficial de Canarias, 2013, № 160, p. 23.137-23.187.

BOLETíN OFICIAL DE CANARIAS (BOC). Dirección General de Trabajo. Resolución de 11 de junio de 2014, por la que se dispone la inscripción, depósito y publicación del Convenio Colectivo de la empresa Binter Canarias, S.A. Boletín Oficial de Canarias, 2014, $N^{\circ} 118$, p. 16.541-16.592.

BOLETíN OFICIAL DEL ESTADO (BOE). Resolución de 21 de julio de 2006, de la Subsecretaría, por la que se dispone la publicación del Acuerdo del Consejo de Ministros de 2 de junio de 2006, por el que se declaran obligaciones de servicio público en rutas aéreas entre las Islas Canarias. Boletín Oficial del Estado, 2006, № 178, p. 28.180-28.185.

BOLETíN OFICIAL DEL ESTADO (BOE). Resolución de 30 de julio de 1998, de la Secretaría de Estado de Infraestructuras y Transportes, por la que se dispone la publicación del Acuerdo del Consejo de Ministros de 10 de julio de 1998, por el que se declaran Obligaciones de Servicio Público en rutas aéreas entre las islas Canarias. Boletín Oficial del Estado, 1998, № 206, p. 29.376-29.380.

BOLETÍN OFICIAL DE LA PROVINCIA DE LAS PALMAS (BOP). Dirección General de Trabajo. Edicto por el que se dispone la inscripción, depósito y publicación del Convenio Colectivo de la empresa Canary Fly, S.L. Boletín Oficial de la Provincia de Las Palmas, 2014, anexo al № 63, p. 623-646.

BURGHOUWT, G. Airline Network Development in Europe and its Implications for Airport Planning. Aldershot: Ashgate, 2007.

CALZADA, J. \& FAGEDA, X. Discounts and Public Service Obligations in the Airline Market: Lessons from Spain. Review of Industrial Organization, 2011, Vol. 40, №4, p. 291-312.

CIVIL AVIATION AUTHORITY (CAA). NoFrills Carriers: Revolution or Evolution? (CAP 770). Londres: Civil Aviation Authority, 2006.

DEBRIE J. \& STECK B. L'enclavement, réévaluation théorique et application à I'Afrique 
de I'Ouest. L'Espace Géographique, 2001, Vol. 30, № 1, p. 26-36.

DOBRUSZKES F. Une géographie des services publics aériens en Europe. L'Espace géographique, 2007, Vol. 36, $\mathrm{N}^{\circ} 4$, p. 320-336.

DOBRUSZKES, F. Libéralisation et desserte des territoires: le cas du transport aérien européen. Bruselas: Peter Lang, 2008.

DOBRUSZKES, F. Does liberalisation of air transport imply increasing competition? Lessons from the European case. Transport Policy, 2009, Vol. 16, № 1, p. 29-39

DIARIO DE SESIONES DEL CONGRESO DE LOS DIPUTADOS (DSCD). Interpelación del Grupo Parlamentario Mixto (señora Oramas), sobre las prioridades y compromisos del Ministerio de Fomento con la Comunidad Autónoma de Canarias (Número de expediente 172/000046) (27 de junio). Diario de Sesiones del Congreso de los Diputados, 2012 (X legislatura), $N^{\circ} 45$, p. 32-38.

DIARIO DE SESIONES DEL SENADO (DSS). Pregunta sobre la fecha prevista por el ministerio para que entre en vigor el control telemático de la acreditación de residente en los territorios no peninsulares para poder viajar (Número de expediente 680/000197) (12 de septiembre). Diario de Sesiones del Senado, 2012 (X legislatura), No 29, p. 1.9101.911.

GRAHAM, B. Liberalization, regional economic development and the geography of demand for air transport in the European Union. Journal of Transport Geography, 1998, Vol. 6, $\mathrm{N}^{\circ} 2$, p. 87-104.

GRAHAM, B. \& GUYER, C. The role of regional airports and air services in the United Kingdom. Journal of Transport Geography, 2011, Vol. 8, N 4, p. 249-262.

GROIZARD CARDOSA, J.L. (coordinador). Estimación de los costes de insularidad de las Illes Balears. Palma de Mallorca: Unviersitat de les Illes Balears, 2014.

GUERRA PALMERO, R.A. Autarquía y Hecho Diferencial Canario (1936-1960). Santa Cruz de Tenerife: Ediciones Idea, 2005.
FAGEDA, X.; JIMÉNEZ, J.L. \& PERDIGUE$\mathrm{RO}, \mathrm{J}$. Price rivalry in airline markets: a study of a successful strategy of a network carrier against a low-cost carrier. Journal of Transport Geography, 2011, Vol. 19, № 4, p. 658-669.

GÁMIR ORUETA, A. y RAMOS PÉREZ, D. Los pequeños aeropuertos regionales de la España peninsular: dinámicas recientes y perspectivas de futuro. Ería, Revista Cuatrimestral de Geografía, 2011, № 84-85, p. 77-102.

GAY, J.-C. L'outre-mer français. Un espace singulier. Paris: Belin, 2008.

HALPERN, N. \& BRÅTHEN, S. Impact of airports on regional accessibility and social development. Journal of Transport Geography, 2011, Vol. 19, No 6, p. 1.145-1.154.

HERNÁNDEZ LUIS, J.A. El transporte aéreo interinsular como factor de cohesión territorial en las Islas Canarias. Transporte y Territorio, 2010, No 2, p. 38-67.

HERNÁNDEZ LUIS, J.A. The role of interisland air transport in the Canary Islands. Journal of Transport Geography, 2004, Vol. $12, N^{\circ} 3$, p. 235-244.

HERNÁNDEZ LUIS, J.A. Transporte aéreo, integración territorial y desarrollo socioeconómico en Canarias. Las Palmas de Gran Canaria: Cámara Oficial de Comercio, Industria y Navegación de Las Palmas de Gran Canaria, 1994.

HOYLE, B.S. Islands, transport and development. In: BIAGINI, E. \& HOYLE, B.S. (editors). Insularity and Development: International Perspectives on Islands. London: Pinter, 1999, p. 137-158.

KRUGMAN, P. \& VENABLES, A. Globalization and the Inequality of Nations. Quarterly Journal of Economics, 1995, Vol. 110, No 4, p. 857-880.

LIAN, J.I. Network dependency and airline competition - Consequences for remote areas in Norway. Journal of Air Transport Management, 2010, Vol. 6, № 3, p. 137-143.

MINISTERIO DE FOMENTO. Estudio del impacto en las tarifas del transporte aéreo de 
las subvenciones para los residentes en Canarias, Baleares, Ceuta y Melilla. Madrid: Dirección General de Aviación Civil, 2008.

MINISTERIO DE FOMENTO. Informe sobre la evolución de la conectividad y los precios en los mercados aéreos de Canarias y Baleares. Madrid: Observatorio de Conectividad y Precios; datos febrero 2013, Dirección General de Aviación Civil, 2013a (inédito).

MINISTERIO DE FOMENTO. Informe sobre la evolución de la conectividad y los precios en los mercados aéreos de Canarias y Baleares. Madrid: Observatorio de Conectividad y Precios; datos agosto 2013, Dirección General de Aviación Civil, 2013b (inédito).

MURILLO FORT, C. (coordinador). Coste de la insularidad en Canarias. Las Palmas de Gran Canaria: Consejería de Economía y Hacienda del Gobierno de Canarias, 1992. Disponible en Internet: http://www.gobiernodecanarias.org/hacienda/beha/modules/ sumarios/portadas_publicaciones/119_publicacion.pdf

NICOLAS, T. La circulation comme facteur d'intégration nationale et d'hypo-insularité. Les Cahiers d'Outre-Mer, 2001, N² 216, p. 397-416.

NICOLAS, T. L'hypo-insularité, une nouveIle condition insulaire: I'exemple des Antilles françaises. L'Espace géographique, 2005, Vol. $34, \mathrm{~N}^{\circ} 4$, p. 329-341.

OFFNER J.-M. Les "effets structurants" du transport: mythe politique, mystification scientifique. L'Espace géographique, 1993, Vol. 22, No 3, p. 233-242.

PANTAZIS, N. \& LIEFNER, I. The impact of low-cost carriers on catchment areas of established international airports: The case of Hanover Airport, Germany. Journal of Transport Geography, 2006, Vol. 14, № 4, p. 265-272.

PAPATHEODOROU, A. \& ARVANITIS, P. Spatial evolution of airport traffic and air transport liberalisation: the case of Greece. Journal of Transport Geography, 2009, Vol. $17, N^{\circ} 5$, p. $402-412$
RAMOS PÉREZ, D. ¿Quién viaja en avión?: Una aproximación a la caracterización de los usuarios europeos del transporte aéreo según su nivel de renta, Scripta Nova: Revista electrónica de Geografía y Ciencias Sociales, 2008, Vol. XII, No 270 (48). Disponible en Internet: http://www.ub.edu/geocrit/$\mathrm{xcol} / 102 . \mathrm{htm}$

RAMOS PÉREZ, D. Transporte aéreo, territorio e insularidad en Canarias. Una aproximación en el umbral del siglo XXI. Madrid: Consejería de Obras Públicas del Gobierno de Canarias, 2001.

RAMOS PÉREZ, ESCALONA ORCAO Y GÁMIR ORUETA. Ayudas públicas y oferta de servicios aéreos en los aeropuertos españoles (1996-2010). Boletín de la Asociación de Geógrafos Españoles, 2013, № 61, p. 25-46.

REY LEGIDOS, M.B. Efectos de la liberalización del transporte aéreo sobre el mercado español de vuelos regulares (1989-1997). Madrid: Tesis Doctoral, Universidad Complutense de Madrid, 2000 (inédita).

REY LEGIDOS, M.B. Structural changes in the Spanish scheduled flights market as a result of air transport deregulation in Europe. Journal of Air Transport Management, 2003, Vol. 9, No3, p. 195-200.

SECRETARÍA DE ESTADO DE RELACIONES CON LAS CORTES (SERC). Respuesta del Gobierno a la pregunta escrita 684/6983 del senador Narvay Quintero Castañeda. Secretaría de Estado Relaciones Cortes. Madrid: Secretaría de Estado de Relaciones con las Cortes, 2013. Disponible en Internet: http:// www.senado.es/web/expedientdocblobservlet ? legis $=10 \& i d=28474$.

SUAU-SÁNCHEZ, P. \& BURGHOUWT, G. The geography of the Spanish airport system: spatial concentration and deconcentration patterns in seat capacity distribution, 20012008. Journal of Transport Geography, 2011, Vol. 19, N², p. 244-254.

SUAU- SÁNCHEZ, P. \& BURGHOUWT, G. Connectivity levels and the competitive position of Spanish airports and Iberia's net- 
work rationalization strategy, 2001-2007. Journal of Air Transport Management, 2012, Vol. 18, No 1, p. 47-53.

TAGLIONI, F. Les petits espaces insulaires face à la variabilité de leur insularité et de leur statut politique. Annales de Géographie, 2006, N 652, p. 664-687.

TAGLIONI, F. La périphéricité: du concept au lobby politique. L'Espace Politique, 2007, $\mathrm{N}^{\circ}$ 2. Disponible en Internet: http://espacepolitique.revues.org/index594.html

TAGLIONI, F. L'insularisme: une rhétorique bien huilée dans les petits espaces insulaires. In: SEVIN, O.; GUILLAUD, D. \& CHALEARD, J-L. (director). Comme un parfum d'îles. Paris: Presse Universitaire Paris Sorbonne (PUPS), 2010, p. 421-435.
WILLIAMS. G. \& PAGLIARI, R. A comparative analysis of the application and use of public service obligations in air transport within the EU. Transport Policy, 2004, Vol. $11, N^{\circ} 1$, p. 55-66.

ZEMBRI, P. Les premiers effets spatiaux des recompositions de réseaux aériens en France: des effets d'aubaine fragiles mais une réelle ouverture de nombreuses régions françaises. Flux, 2000, No 41, p. 28-40.

ZEMBRI, P. The Spatial Conséquences of Air Transport dérégulation: an Overview of the French Case since 1995. In: VAN GEENHUIZEN, M.; REGGIANI, A. \& RIETVELD, P. Policy Analysis of Transport Networks. Aldershot: Ashgate, 2007, p. 235-256. 
